\title{
The role of polyphenols in overcoming cancer drug resistance: a comprehensive review
}

\author{
Parisa Maleki Dana ${ }^{1}$, Fatemeh Sadoughi ${ }^{1}$, Zatollah Asemi ${ }^{1 *}$ and Bahman Yousefi ${ }^{2,3^{*}}$
}

\author{
${ }^{*}$ Correspondence: \\ asemi_z@Kaums.ac.ir; \\ bahmanusefi@gmail.com \\ ${ }^{1}$ Research Center \\ for Biochemistry \\ and Nutrition in Metabolic \\ Diseases, Institute for Basic \\ Sciences, Kashan University \\ of Medical Sciences, Kashan, \\ Islamic Republic of Iran \\ ${ }^{2}$ Molecular Medicine \\ Research Center, Tabriz \\ University of Medical \\ Sciences, Tabriz, Iran \\ Full list of author information \\ is available at the end of the \\ article
}

\begin{abstract}
Chemotherapeutic drugs are used to treat advanced stages of cancer or following surgery. However, cancers often develop resistance against drugs, leading to failure of treatment and recurrence of the disease. Polyphenols are a family of organic compounds with more than 10,000 members which have a three-membered flavan ring system in common. These natural compounds are known for their beneficial properties, such as free radical scavenging, decreasing oxidative stress, and modulating inflammation. Herein, we discuss the role of polyphenols (mainly curcumin, resveratrol, and epigallocatechin gallate [EGCG]) in different aspects of cancer drug resistance. Increasing drug uptake by tumor cells, decreasing drug metabolism by enzymes (e.g. cytochromes and glutathione-S-transferases), and reducing drug efflux are some of the mechanisms by which polyphenols increase the sensitivity of cancer cells to chemotherapeutic agents. Polyphenols also affect other targets for overcoming chemoresistance in cancer cells, including cell death (i.e. autophagy and apoptosis), EMT, ROS, DNA repair processes, cancer stem cells, and epigenetics (e.g. miRNAs).
\end{abstract}

Keywords: Polyphenols, Curcumin, Resveratrol, Epigallocatechin gallate, Chemoresistance

\section{Introduction}

Localized solid tumors are often treated with surgery in their early stages. However, other treatment modalities are applied at advanced stages and/or following the surgery, such as targeted therapies, radiotherapy, immunotherapy, and chemotherapy [1]. Advances made in the field of antitumor agents have led to a significant increase in patients' life quality and disease-free survival [2]. Despite the importance of chemotherapeutic drugs, there are significant drawbacks in using them to treat cancer, such as solubility and instability of drugs, nonspecific drug delivery, and adverse effects due to systemic toxicity [3]. Furthermore, recurrence and relapse of cancer occur in some patients even after a favorable response at the beginning of the treatment. Indeed, acquired drug resistance has become an important challenge that results in the failure of cancer treatment [2]. Both acquired and intrinsic processes can lead to chemoresistance in cancer cells [4]. Acquired drug resistance indicates a newly developed resistance against a therapeutic approach that was effective at the beginning. 
Intrinsic chemoresistance involves a pre-existing factor that causes a drug to be inefficient [5]. Tumor cells' heterogeneity is one of the factors leading to chemoresistance. Stem-like cancer cells are renewable subpopulations of tumor cells that are responsible for heterogeneity. There are various cell generations within one tumor, and each clone is sensitive to chemotherapeutic agents to some degree. Therefore, targeting tumor cells with a single agent may not lead to a favorable response [6-8]. Increased drug efflux, changes in the target of drugs, apoptosis, and repair signaling pathways are other mechanisms involved in the resistance of cancer cells to chemotherapeutic drugs $[4,9]$.

\section{Polyphenols and their therapeutic application in cancer}

Polyphenols are a large family of 10,000 plant compounds that are known for their common structural features including the three-membered flavan ring system and multiple phenol units $[10,11]$. These natural compounds are mostly found in fruits, green and black tea, coffee, red wine, cocoa, and seeds [12]. These beneficial organic agents are categorized into several subclasses including catechins, flavonoids (which contain flavonols, flavanols, and flavones), anthocyanins, catechins, isoflavones, chalcones, curcuminoids, and phenolic acids (structures are shown in Fig. 1) [12, 13].

The idea of using polyphenols for treating cancer patients is not new. Early studies considering the anti-cancer effects of different polyphenols were conducted in the late twentieth century and our knowledge on these advantageous agents has been widely improved since then $[14,15]$. What makes these agents greatly beneficial and interesting is that they attack cancer cells in a variety of ways and confront many cancer hallmarks (summarized in Fig. 2). Therefore, we shall briefly discuss different aspects of polyphenols' effects in this section.

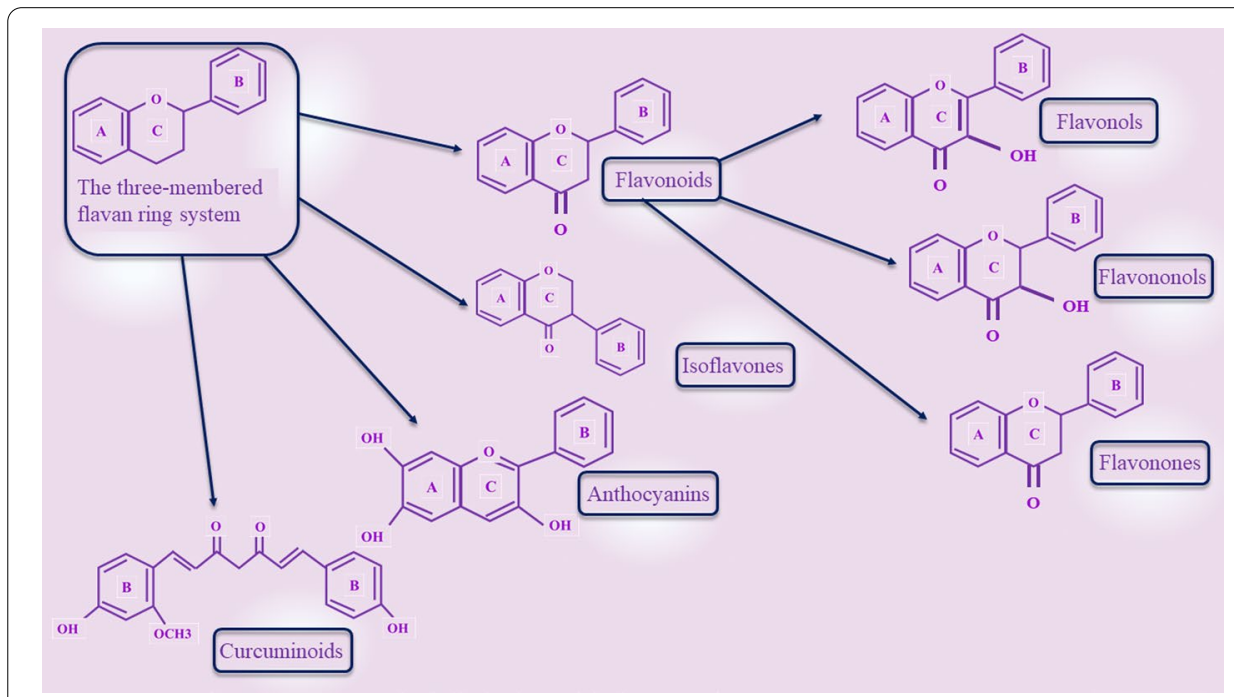

Fig. 1 Schematic representation of different structures of polyphenols. These agents have a three-membered flavan ring system in common 


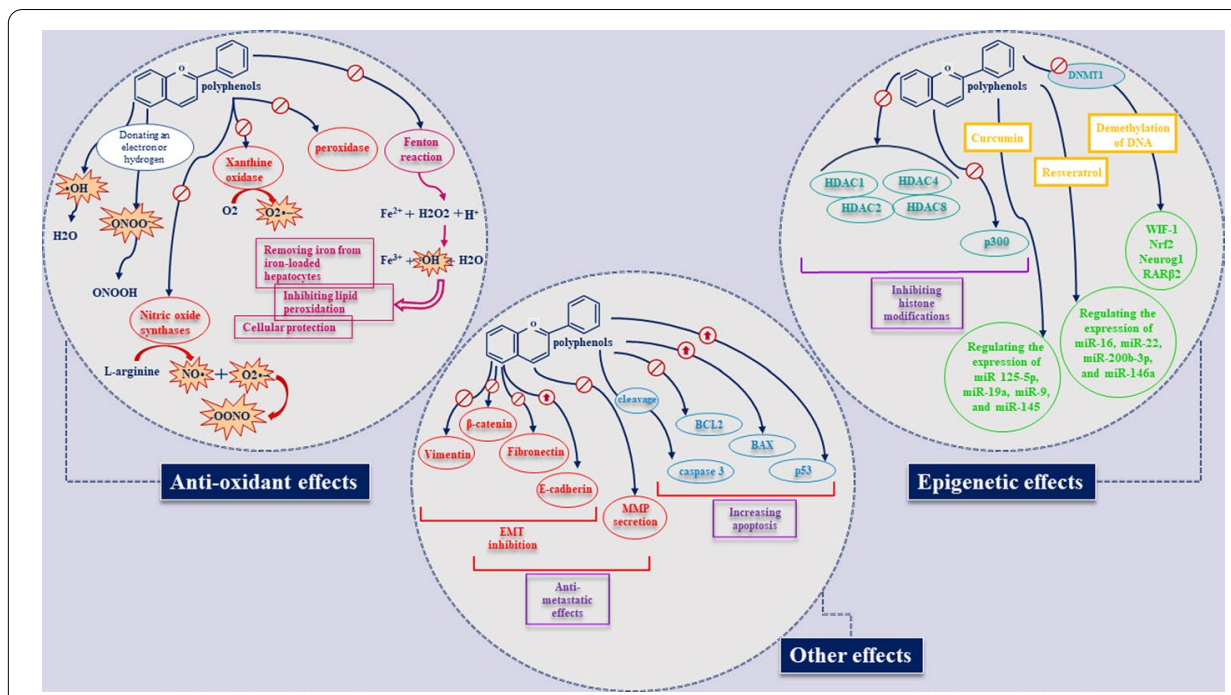

Fig. 2 Some of the anti-cancer effects of polyphenols including epigenetic, anti-metastatic, pro-apoptotic, and anti-oxidant impacts

\section{Antioxidant effects}

The anti-oxidant impacts of polyphenols are possible through either scavenging free radicals or building a barrier against their generation (Fig. 2) [10]. The main free radicals that exist in our cells and cause oxidative stress are reactive oxygen species (ROS) and reactive nitrogen species (RNS) [16]. The former mechanism of polyphenols' action relies on the presence of benzene ring-bound hydroxyl groups which provide the ability to donate a hydrogen atom or an electron to free radicals [17]. This occurrence stabilizes free radicals and prevents them from damaging the cellular components [17]. It seems that the B ring of polyphenols plays the most important role in scavenging hydroxyl, peroxyl, and peroxynitrite radicals [17]; however, the scavenging property can also be dependent on other structural parts in different polyphenols. For instance, in flavonoids, which are the best known polyphenols, a free $3-\mathrm{OH}$ is mostly responsible for neutralizing the free radical [18].

As mentioned above, polyphenols also have the capacity to inhibit the generation of ROS and RNS by interfering with the enzymes involved in their production. Nitric oxide synthases (NOS), xanthine oxidase (XO), and peroxidase are some of these enzymes, whose activity can be altered when certain interactions occur between them and polyphenols $[19,20]$. Xanthine oxidase is one of the most important enzymes that generate superoxide from oxygen molecules [21]. Quercetin, kaempferol, myricetin, and chrysin are among the polyphenols that are confirmed to inhibit this enzyme [22]. NOS is also essential for producing nitric oxide in endothelial cells and macrophages. Nitric oxide mediates oxidative stress by increasing the production and concentration of peroxynitrite and thereby damaging the cellular membrane [20]. Anthocyanidins are a subclass of polyphenols that prevent NOS from generating nitric oxide and thereby repressing their .NO scavenging capacity [23].

Another production mechanism that is prone to be affected by the chelating properties of polyphenols is the metal-mediated reduction of peroxides [24]. In this 
mechanism, which is known as the Fenton reaction, $\mathrm{Fe}^{2+}$ ions reduce $\mathrm{H}_{2} \mathrm{O}_{2}$ and thereby create a hydroxyl radical which is harmful to cells $[24,25]$. In this concentration-dependent process, polyphenols can interfere as chelating agents and form stable complexes with iron [24]. Inhibiting lipid peroxidation, removing iron from iron-loaded hepatocytes, blocking the Fenton reaction, and cellular protection are the results of the interactions between diverse polyphenols and iron [25-28].

\section{Effects on apoptosis}

As regards apoptosis, a great number of polyphenols are able to induce cell death by altering the expression of apoptosis-related genes. Curcumin is one of the most investigated polyphenols, which increases apoptosis in cancer cells through a variety of mechanisms, for instance, diminishing the intracellular ROS, phosphorylation, and activation of mitogen-activated protein kinase (MAPK) signaling pathway [29], increasing intracellular Ca influx and activating calcium/calmodulin-dependent protein kinase II (CaMKII) signaling [30], increasing PI3K/Akt protein expression (31), inducing p53 expression (32), regulating miRNAs [33], reducing the levels of B-cell lymphoma 2 (BCL2), inducing BCL-2-associated X protein (BAX), and cleaving caspase 3 [34]. Resveratrol is another beneficial polyphenol that is observed to have an effect on apoptosis in many types of cancer including bladder [35], prostate [36], breast, lung, glioblastoma, colon, and ovarian [37-42]. For instance, resveratrol suppresses proliferation and migration of ovarian cancer SKOV3 and A2780 cells. Also it impairs glycolysis and induces apoptosis. Evidence shows that treating cells with resveratrol reduces both activation and expression of mTOR and downstream kinase of AMPK while increasing the activation and expression of caspase- 3 and AMPK. In vivo findings also indicated that resveratrol inhibits the growth of ovarian cancer as well as liver metastasis in a mouse xenograft model [38]. In vitro findings demonstrate that EGCG inhibits the viability of oral squamous cell carcinoma HSC-3 cells. Moreover, it induces cell cycle arrest at the G1 phase. EGCG has also been shown to significantly increase the activity of caspase- 3 and -7 as well as apoptotic cells. In vivo investigations on mice xenograft models indicated that EGCG leads to a $42.5 \%$ reduction in the size of the tumor compared with the control group. Furthermore, the percentage of apoptotic cells is higher in mice treated with EGCG [43].

\section{Changes in cell cycle and inhibition of proliferation}

Cell cycle arrest is another anti-cancer effect of these plant compounds which is exerted by resveratrol, curcumin, and diverse flavonoids in cancer cells $[40,44,45]$.

\section{Anti-metastatic effects}

Metastasis is defined as a series of concurrent mechanisms which help the tumor cells gain the ability to migrate from their primary site to other sites of the body and increase the cancer lethality [46]. Metastasis occurs as a result of the effects of microenvironmental ingredients such as stromal fibroblasts and immune cells on the tumor cells. Cellular motility, hypoxia, EMT, and angiogenesis are the primary mechanisms that prepare tumoral cells for infiltration [47-49]. According to research, matrix metalloproteinases (MMPs), TGF- $\beta$, and TP53 have essential roles in managing metastasis [47-49]. 
Polyphenols have shown their capabilities in influencing several steps of this process. For instance, curcumin affects the EMT-related proteins including vimentin, fibronectin, $\beta$-catenin, and $E$-cadherin along with the genes expressed in cancer stem cells such as Oct4, Nanog, and Sox2, and thereby decreases the metastatic features of cancer cells [50]. Quercetin and its derivatives are also effective for inhibiting EMT, MMP secretion, NF-kappaB, and migration of the cancer cells and thus metastasis [51-55]. Reversing EMT through AKT/GSK-3 $\beta /$ Snail signaling and diminishing the levels of MMP-2 and 9, and Smad 2 and 3 are the anti-metastasis effects of resveratrol $[56,57]$.

\section{Epigenetic effects}

Epigenetic dysregulations and abnormalities are the basis of tumor initiation, progression, and resistance to therapy [58]. DNA methylation, histone modifications, chromatin/nucleosome remodeling, and miRNA regulation are some of the epigenetic alterations which are involved in a variety of cancer features [58].

Curcumin is one of the most efficient polyphenols in preventing these alterations from aiding the cancer cells. Histone deacetylases (HDACs) are a class of gene silencingrelated enzymes that diminish the number of acetyl groups from histones [59]. One of curcumin's effects is to inhibit these enzymes and thereby regulate the proliferation and apoptosis of various cancer cells [60]. HDAC1, HDAC2, HDAC3, HDAC4, and HDAC8 can be inhibited by curcumin [60-63]. Histone acetyltransferases (HATs) are another class of enzymes that also predict cancer cell growth and survival. One of these enzymes is $\mathrm{p} 300$, which has been shown by some investigations to be inhibited by curcumin, through either a direct or indirect manner [64, 65].

Furthermore, curcumin suppresses DNA methylation in the promoter region of many cancer-related genes, including the tumor suppressor gene Wnt inhibitory factor-1 or WIF-1 [66], FANCF [67], Nrf2 [68], Neurog1 [69], and RAR $\beta 2$ [70] through decreasing the DNA methyltransferase 1 level (DNMT1) [71, 72].

Regulating the amounts of microRNAs is a newly discovered aspect of curcumin's effect in the field of cancer therapy which we have discussed in detail in our previous paper [73]. miR-125-5p, miR-19a, miR-9, and miR-145 are some of the miRNAs affected by curcumin in nasopharyngeal, breast and ovarian cancers and leukemia [74]. Regarding other polyphenols, resveratrol is also able to modulate miR-200, miR-122-5p, miR20, and miR-633 [75-78]. miR-16, miR-22, miR-200b-3p, and miR-146a are some of the miRNAs regulated by quercetin in cancerous cells [79-82]. Epigallocatechin-3-gallate, genistein, and DIM also contribute to reversing epigenetic alterations in cancer cells via diverse microRNAs [83, 84].

\section{Polyphenols modulate cancer drug resistance}

Several studies have reported that polyphenols can affect different aspects of cancer drug resistance. Herein, we provide a brief discussion on how each mechanism changes the sensitivity of cancer cells to chemotherapeutic drugs. Furthermore, we review the literature on the role of polyphenols (mainly curcumin, resveratrol, and EGCG) in overcoming cancer drug resistance by each of these mechanisms. 


\section{Drug uptake by tumor cells}

Facilitation of diffusion, passive transfer, and active transport are different types of drug absorption to the tumor cells [85]. Decreased drug uptake is a mechanism by which tumor cells develop chemoresistance against therapeutic agents [86]. The reduced tendency for binding to drugs is a common process that leads to decreased drug absorption. Another mechanism is decreased number of transporters [87]. Drug formulations based on nanotechnology have attracted a lot of attention in recent years due to various reasons, such as targeted drug delivery, ability to encapsulate multiple agents, higher biocompatibility, decreased side effects, and slow release rate. Another important advantage of nano-formulations is the ability to enhance bioavailability of drugs and overcome chemoresistance [88]. Among other beneficial effects, nanoformulations lead to an increase in cellular drug uptake. Several studies have been conducted on the role of polyphenols in designing nanomaterials for drug delivery. Tsai and colleagues prepared gold nanoparticles based on gelatin-doxorubicin (DOX) and EGCG to suppress the growth of prostate cancer. They reported that Au nanoparticles that are coated with EGCG and gelatin-DOX efficiently deliver DOX through the laminin 67R receptor and increase the cellular uptake of the drug [89]. Studies have also demonstrated that using EGCG leads to the reduction of $\mathrm{Au}^{3+}$, providing enhanced Au nanoparticles that show higher drug uptake by cancer cells [90-92].

Reduced intracellular accumulation of platinum-based antitumor agents (e.g. cisplatin) has been associated with chemoresistance of tumors. Proteins playing a role in the hemostasis of copper are reported to be transporters of platinum. Copper transporter 1 (CTR1) is the main influx transporter of copper which is involved in the resistance to platinum [93]. Wang et al. [94] reported that EGCG increases the expression of CTR1 at mRNA and protein levels in ovarian cancer cells as well as xenograft mice. Indeed, EGCG treatment suppresses the rapid cisplatin-induced degradation of CTR1 and enhances the cellular accumulation of cisplatin and DNA-Pt adducts. This causes an increase in the sensitivity of OVCAR3 and SKOV3 ovarian cancer cells to cisplatin [94]. Another study also showed that EGCG upregulated CTR1 while increasing the accumulation of platinum in non-small cell lung cancer (NSCLC) cells (including H460, H1299, and A549), a xenograft model of nude mice, and cisplatin (cDDP)-resistant A549 cells. It was found that hsa-mir-98-5p inhibits expression of the CTR1 gene. Meanwhile, lncRNA nuclear enriched abundant transcript 1 (NEAT1) increases the expression of NEAT1. Indeed, NEAT1 is suggested to increase EGCGinduced CTR1 through sponging hsa-mir-98-5p. Therefore, EGCG enhances the sensitivity of NSCLC cells to cisplatin both in vitro and in vivo [95]. MRP1 regulates both absorption and disposition of various xenobiotic and endogenous substrates, such as drugs, across different physiological barriers [96]. In DOX-resistant acute myeloid leukemia (AML)-2/DX300 cells, the expression level of the MRP1 gene is reported to be higher compared to the wild-type AML-2/WT cells. Treating this chemoresistant cell line with resveratrol leads to a reduction in MRP1 expression. Furthermore, the absorption of the MRP1 substrate 5(6)-carboxyfluorescein diacetate is reported to be enhanced by resveratrol. Therefore, it is suggested that resveratrol may enhance DOX cellular absorption by reducing the gene expression of MRP1 [97]. 


\section{Drug efflux}

The main cause of multi-drug resistance in cancer cells is the increased efflux of antitumor agents through drug transporters which are embedded in the membrane [98]. P-glycoprotein (p-gp/ABCB1/MDR1) is a member of the ATP-binding cassette (ABC) superfamily which acts as a drug transporter in humans. Multidrug resistance protein 1 (MRP1/ABCC1) and breast cancer resistant protein (BCRP/BCP/MXR/ABCG2) are other well-studied drug transporters of the $A B C$ superfamily [99-102].

P-gp is a pump involved in drug efflux and is associated with multi-drug resistance [103]. In response to chemotherapeutic agents, p-gp is upregulated, which, in turn, leads to a reduction in the drugs' intracellular accumulation and decreases the efficacy of drugs [104]. Didox is a polyhydroxyphenol that serves as a chemo-sensitizer. In HCT 116 colorectal cancer cells, the combination of didox and resveratrol with DOX leads to the reduction of DOX $\mathrm{IC}_{50}$ from $0.96 \pm 0.02 \mu \mathrm{M}$ to $0.4 \pm 0.06 \mu \mathrm{M}$ and $0.52 \pm 0.05 \mu \mathrm{M}$, respectively. Both didox and resveratrol significantly increase DOX intracellular entrapment by preventing the efflux effect of p-gp [105]. EGCG is shown to modulate p-gp function and enhance the intracellular entrapment of DOX in drug-resistant KB-A1 cells. Indeed, combination of $50 \mu \mathrm{M}$ of EGCG with $10 \mu \mathrm{M}$ DOX for $4 \mathrm{~h}$ increases the DOX intracellular concentration by 2.3 times in KB-A1 cells compared to treatment with DOX alone. Furthermore, in vitro studies and xenograft models confirmed that EGCG enhances the antitumor activities of DOX in drug-resistant tumors [106]. Liang et al. also reported that EGCG or epicatechin gallate (ECG) at higher doses slightly suppressed the proliferation of resistant human hepatocellular carcinoma (HCC) BEL-7404/ DOX cells in vitro and in vivo. Meanwhile, lower doses of the mentioned compounds with DOX lead to significant suppression of HCC cell proliferation in vitro as well as growth of hepatoma in a mouse xenograft model compared to administration of either agent alone. Using EGCG or ECG in combination with DOX increases the intracellular accumulation of DOX, suggesting that catechins suppress the activity of the P-gp efflux pump. Furthermore, this combinational treatment enhanced the intracellular retention of a P-gp substrate, rhodamine 123, while reducing the expression of mRNA of HIF-1 $\alpha$ and MDR1 [107].

Research has shown that some cancer cells are dependent on the PI3K/Akt/mTOR pathway in order to survive following DNA damage. Therefore, the repair of DNA damage can be inhibited by suppressing this signaling pathway, which, in turn, increases the sensitivity to radio- and chemotherapy [108]. In K562/ADR cells, overexpression of p-gp reduces the cytotoxic effects of antitumor agents and consequently multi-drug resistance occurs. Treating K562/ADR cells with a combination of resveratrol and bestatin results in a decrease in bestatin's $\mathrm{IC}_{50}$ values and enhances the bestatin-induced apoptosis. Resveratrol exerts this potentiating effect by suppressing the activity of p-gp and lowering mRNA and protein levels of p-gp. In addition, resveratrol reduces the phosphorylation of mTOR and Akt without affecting ERK1/2 and JNK. Thus, it is implied that the resveratrol inhibitory effect on p-gp is mediated by inhibition of the PI3k/Akt/ mTOR pathway [109].

Through active drug efflux, MRP5 causes drug resistance against gemcitabine and 5-fluorouracil (5-FU). Curcumin is shown to increase the sensitivity of MRP5 overexpressing HEK293, PANC-1, and MiaPaCa-2 cells to 5-FU. Therefore, it is suggested 
that curcumin can act as an inhibitor of MRP5 while reversing multidrug resistance in pancreatic cancer [110]. Curcumin increases DOX anticancer effects in DOX-resistant breast cancer MDA-MB-231/DOX and MCF-7/DOX cell lines [111]. It is observed that curcumin treatment leads to an increase in DOX intracellular accumulation. The mentioned effect is negatively associated with the activity of ATP binding cassette subfamily $\mathrm{B}$ member 4 (ABCB4). Treating cells overexpressing $\mathrm{ABCB} 4$ with $\mathrm{DOX}$ and curcumin reduces DOX efflux. In addition, ABCB4 ATPase activity is suppressed by curcumin without any changes in its protein expression (111).

\section{Alteration in drug metabolism}

Evidence has indicated that following treatment with antitumor agents, some cell-protective gene products are induced. In phase I and phase II of drug metabolism, some enzymes are involved which are useful for the detoxification from harmful endogenous and exogenous compounds. In phase I of drug metabolism, different cytochrome isoforms are involved, including CYP1A2, CYP1A6, CYP1B1, CYP2B6, and CYP2C19 [112]. It is reported that curcumin suppresses the activity of CYP3A while increasing the rhodamine-123 intracellular accumulation in MCF-7/ADR cells that overexpress p-gp. Curcumin treatment also significantly increases the bioactivity of tamoxifen. It is suggested that curcumin may suppress the cytochrome-mediated metabolism of tamoxifen to 4-hydroxyfamoxifen, an active metabolite of tamoxifen, as evidenced by the reduced metabolite-parent AUC ratio. Therefore, curcumin-mediated enhanced bioavailability of tamoxifen is probably mediated by the suppression of tamoxifen metabolism in the liver and the small intestine [113].

Gamma-glutamyl transferases (GGTs), thiopurine methyltransferases (TPMTs), glutathione- $\underline{S}$-transferases (GSTs), dihydropyrimidine dehydrogenases (DPDs), and uridine diphospho-glucuronosyltransferases (UGTs) are enzymes playing roles in phase II of drug metabolism. The altered expression of these enzymes may cause multidrug resistance in cancer cells $[114,115]$. Curcumin is shown to reduce the activity of gamma-glutamyl transpeptidase (GGTP) in ZR-75-1 mammary cells which are resistant to oxidative damage [116]. Studies have reported that a moderate reduction in the levels of glutathione can enhance the sensitivity of tumor cells to chemotherapeutic agents [117]. GSTs are observed to be overexpressed in different cancers (e.g. cancers of breast, liver, and lung) and lead to drug resistance [118-120]. Therefore, suppressing GST is suggested to help overcome cancer resistance to chemotherapeutic drugs. Derivatives of flavonoids (e.g. baicalin, phloretin, baicalein, and phloridzin) are reported to be related to the suppression of GST functions [121]. Curcumin and ellagic acid are capable of inhibiting GSTs M1-1, M2-2, A1-1, A2-2, and P1-1 while using 1-chloro-2,4 dinitrobenzene (CDNB) as a substrate [122]. Curcumin analogs (i.e. 2,6-dibenzylidenecyclohexanone, 2,5-dibenzylidenecyclopentanone, and 1,4-pentadiene-3-one) are also shown to exert inhibitory effects on GSTs. However, their inhibitory effects on GTS A1-1, GTS M1-1, and GST P1-1 are smaller compared to curcumin [123]. Galangin is a flavonoid that suppresses the cellular activity of GST P1-1 at a concentration of $25 \mu \mathrm{M}$ in GST P1-1 transfected MCF-7 breast cancer cells. Quercetin, kaempferol, and eriodictyol are other flavonoids that moderately inhibit the activity of GST P1-1. Most flavonoids (mainly quercetin and luteolin) are shown to inhibit GS-X pump transport. However, 
flavonoids without a C2-C3 double bond (e.g. catechin and eriodictyol) do not suppress the activity of the GS-X pump [124].

\section{Epigenetics}

Epigenetic modification indicates some reversible changes in the expression of genes without causing changes in the sequence of DNA [125]. Mechanisms involved in epigenetics are capable of driving acquired cancer resistance against chemotherapeutic drugs. Epigenetic alterations occur at a high rate in tumors, leading to the diverse patterns of gene expression that cause drug resistance [126]. Since drug resistance can be reversed and it shows rapid kinetics and absence of genetic mutations, epigenetic mechanisms may be involved in insensitivity to drugs [127]. Epigenetic processes form different states of transcription which lead to a dynamic heterogeneous nature in the population of tumor cells [127]. As already mentioned, there are a number of mechanisms leading to epigenetic alterations, among which the role of miRNAs in the development of drug resistance in cancer is greatly investigated [128-130]. Therefore, targeting epigenetic changes and miRNAs with polyphenols may be a potential approach to overcome cancer drug resistance.

\section{Resveratrol}

DNA methylation by resveratrol has been explored by a very limited number of studies. Zadi Heydarabad and colleagues showed that DNA methylation of BAX and BCL2 genes in a T-cell acute lymphoblastic leukemia cell line, CCRF-CEM, can be detected after resveratrol treatment by a methylation-specific polymerase chain reaction technique. They suggested that this observation might explain the effect of resveratrol in sensitizing ALL cells to apoptosis [131]. In another study, the effect of resveratrol on retinoic acid resistance in the anaplastic thyroid cancer cell line THJ-11T and the human medulloblastoma UW228-2 cell line showed that resveratrol not only demethylates the cellular retinoic acid binding protein 2 (CRABP2) promotor but also decreases the amounts of some DNA methyltransferases such as DNMT1, 3A, and 3B [132]. Despite these studies, Zadi Heydarabad et al. [133] in another investigation found no relation between resveratrol and human multidrug resistance gene 1 (MDR1) methylation in the CCRF-CEM cell line; therefore, other drug resistance-related genes should be examined to clarify whether resveratrol is involved in DNA methylation-related drug resistance.

From another point of view, resveratrol induces apoptosis and enhances chemosensitivity to Adriamycin in MCF-7 breast cancer cells. It has been shown that the mentioned effects of resveratrol are inhibited by modulation of miR-122-5p, which is a critical suppressor. Moreover, modulation of miRNA by inhibitors or mimics of miR-122-5p demonstrate that miR-122-5p is involved in the regulation of CDKs (i.e. CDK2, CDK4, and CDK6) and anti-apoptotic factors (e.g. BCL-2) following resveratrol treatment [77].

\section{Quercetin}

Quercetin with a concentration of $5 \mu \mathrm{M}$ improves the sensitivity of osteosarcoma 143B cells to cisplatin. Furthermore, it upregulates miR-217 expression while downregulating the expression of KRAS, which is the miR-217 target. Moreover, knockdown of miR217 is shown to hinder quercetin-induced increased sensitivity to cisplatin. Therefore, 
quercetin's ability to enhance cisplatin sensitivity is modulated by the miR-217-KRAS axis [134]. In the U-87 MG glioblastoma cell line, curcumin increases expression of miR146a and enhances temozolomide-induced apoptosis. However, miR-146a inhibits the enhanced anti-tumor action of temozolomide which is induced by curcumin. Meanwhile, upregulation of miR-146a inhibits the activation of NF-kB and increases apoptosis in cells treated with temozolomide [135]. It seems that quercetin's ability is not limited to microRNA regulation and DNA methylation and histone modifications can also be affected by this beneficial agent $[136,137]$; however, these effects have not been examined in cancerous cells, and thus further investigations might expand the range of quercetin's potential application.

\section{Curcumin}

According to evidence, curcumin is one of the most important polyphenols in regulating epigenetic alterations of cancerous cells $[73,74]$; nonetheless, its efficacy in sensitizing tumoral cells to chemotherapeutic drugs is still controversial. In an in vitro study on the SiHa cell line, Roy and Mukherjee found that curcumin increases the effect of cisplatin on cervical cancer cells through several mechanisms including inhibition of histone deacetylase 1 (HDAC1) [138]. Royt et al. also confirmed that histone deacetylase can be decreased after curcumin treatment in the MCF-7 (ER positive) cell line [139]. Despite the small number of studies on DNA methylation and histone modification after curcumin treatment, the role of this agent in microRNA regulation has been intensively studied. Resistance to cisplatin in the A2780cp ovarian cancer cell line can be reduced indirectly by curcumin: demethylation in the promoter region of MEG3 occurs after curcumin usage, which leads to the down-regulation of miR-214. This microRNA is able to establish chemoresistance through increasing the capability of extracellular vesicles [140]. Decreased resistance to is also observed after treating Adr-resistant MCF-7 cells with curcumin-encapsulated liposomes [141]. Curcumin decreases the resistance to Adriamycin via altering the expression of some microRNAs including miR-29b-1-5p [141]. Overcoming Adriamycin-resistance has also been examined in human acute myeloid leukemia cells (HL-60) [142]. It seems that miR-20a-5p mediates the anti-resistant effects of curcumin in these cells and, overall, the HOTAIR/miR-20a-5p/WT1 pathway is the reason that curcumin can sensitize AML cells to Adriamycin (in vitro and in vivo) [142].

microRNA-27a is another microRNA whose down-regulation can result in lower resistance to 5-fluorouracil in SW-480 colon cancer cells [143]. Curcuminoids (2.5$10 \mu \mathrm{g} / \mathrm{mL}$ ) disrupt the axis of miR-27a-ZBTB10-Sp and thereby suppress the expression of multidrug resistance protein (MDR1) [143]. Paclitaxel resistance, which is considered as a major issue in the treatment of aggressive non-small-cell lung cancers, is detected to be suppressed through the axis of mirRNA-30c/MTA1. The metastasis-associated gene 1 (MTA1) gene is reduced in these cells due to the up-regulation of microRNA-30c by curcumin (in vitro) [144].

\section{Cell death}

Similar to cell growth and division, a key component of homeostasis is programmed cell death. Apoptosis, necrosis, and autophagy are three types of programmed cell death that 
are involved in development [145]. Several studies have been conducted on the underlying mechanisms of apoptosis in the past two decades. These investigations demonstrate that apoptosis involves different signaling pathways which are associated with survival pathways and change the phenotype of cells, such as drug resistance [146]. Apoptosis is a programmed cell death that removes aged and damaged cells from the body. In cancer, apoptotic signaling is dysregulated. Indeed, anti-apoptotic pathways are activated in cancer cells, which results in uncontrolled proliferation of cells, leading to drug resistance and tumor recurrence [147]. Autophagy is a mechanism of homeostatic cellular recycling which is involved in the response to therapeutic and metabolic stresses. By autophagy, the body tries to maintain or restore the homeostasis of metabolism via catabolic lysis [148]. Evidence has shown that cancer therapeutic approaches are capable of inducing autophagy. Meanwhile, autophagy is demonstrated to enhance the survival of tumor cells and lead to therapy resistance in some cases [149].

Gefitinib is an epidermal growth factor receptor (EGFR) tyrosine kinase inhibitor (TKI) which is used for treating patients with NSCLC. However, cases with wild-type mutations of KRAS and EGFR are resistant to this therapeutic agent. Curcumin is shown to increase the anti-tumor effects of gefitinib against the H1299 and H157 gefitinibresistant NSCLC cell lines. Treating these cells with the combination of curcumin and gefitinib leads to the induction of autophagy and autophagy-mediated apoptosis. Pharmacological inhibitors of autophagy, 3-MA, or Bad A1 are also shown to reverse the synergistic effect of curcumin and gefitinib [150]. Resveratrol exerts anti-tumor effects against human oral cancer CAR cells while showing low toxicity in normal oral cells. As evidenced by acridine orange (AO) and monodansylcadaverine (MDC) staining, resveratrol treatment leads to the formation of autophagic vacuoles and acidic vesicular organelles. Furthermore, resveratrol induces expression of autophagy-related genes at the mRNA level, including Beclin-1, Atg5, Atg12, and LC3-II. It also leads to apoptosis as evidenced by DNA condensation or DNA fragmentation. Resveratrol-induced cleavage of caspase- 3 and -9 as well as apoptosis is reduced by Z-VAD-FMK, a pan-caspase inhibitor. Moreover, inhibitors of PI3K class III and AMPK (3-MA and compound c, respectively) lead to inhibition of autophagic vesicle formation and protein levels of LC3-II [151].

In a methotrexate (MTX)-resistant osteosarcoma cell line (U2-OS/MTX300), quercetin plays antitumor roles without showing cross-resistance with MTX. As evidenced by fluorescence staining and cytometry, quercetin induces apoptosis in these cells. Apoptosis is paralleled by mitochondrial cytochrome c release to the cytosol, reduced mitochondrial membrane potential, Akt dephosphorylation, upregulation of caspase- 3 and Bax as well as downregulation of $\mathrm{p}-\mathrm{Bad}$ and Bcl-2. Notably, constitutive activation of Akt hinders quercetin-mediated Akt and Bad dephosphorylation as well as degradation of poly(ADP-ribose)polymerase (PARP) [152]. In human leukemic multidrug-resistant K562/Adriamycin (ADR) cells, the combination of Adriamycin and quercetin leads to enhanced cytotoxicity. Quercetin treatment enhances the apoptosis of tumor cells. Indeed, it increases the expression of $\mathrm{Bcl}-2$-associated death promotor, $\mathrm{Bcl}$-2-interacting mediator of cell death, and $\mathrm{Bcl}-2$-associated $\mathrm{X}$ protein. Also, it reduces the potential of mitochondrial membrane potential as well as expression of Bcl-2 while activating caspase-3, -8, and -9 [153]. In cisplatin-resistant oral cancer CAR cells, EGCG induces 
apoptosis and autophagy. EGCG increases the protein levels of cleaved caspase-3 and -9 as well as their activities. Additionally, it enhances the protein levels of Bax, Beclin-1, LC3B-II, Atg5, Atg7, and Atg12. Meanwhile, it decreases the Bcl-2 expression, STAT3 phosphorylation of Tyr705, and Ser473 (phosphorylated AKT). The expression of multidrug resistance 1 (MDR1) is also suppressed by EGCG at gene and protein levels [154] (Table 1).

\section{Alterations in DNA repair}

DNA damage response (DDR) is a collection of mechanisms involved in detecting DNA damage and signaling it, which lead to either DNA repair processes or cell death pathways $[161,162]$. DDR plays a protective role for the human genome against damage through removing errors and inhibiting mutation insurgence under physiological conditions. However, DNA repair systems work in favor of tumor cells following treatment with DNA damaging agents, causing failure in treatment [163].

Excision repair cross-complementation group 1/xeroderma pigmentosum group $\mathrm{F}$ (ERCC1/XPF) is an endonuclease that is involved in DNA damage repair following cisplatin treatment. The green tea polyphenol (-)-epigallocatechin-3-gallate (EGCG) is shown to inhibit the activity of ERCC1/XPF and DNA repair, leading to enhanced sensitivity of non-small cell lung cancer cell lines to cisplatin. Moreover, in vivo examination of this agent in 20 female athymic mice showed that EGCG octaacetate, an EGCG prodrug, improves the efficacy of platinum-based chemotherapy [164]. Thymidine phosphorylase is an enzyme in the pyrimidine salvage pathway which hinders DNA damageinduced cell death in cancer cells [165]. Curcumin treatment reduced the expression of thymidine phosphorylase at mRNA and protein levels in non-small-cell lung cancer. Furthermore, it downregulated ERCC1 by inactivating MKK1/2-extracellular signal-regulated kinase (ERK1/2). A similar study also indicated that demethoxycurcumin is able

Table 1 Polyphenols that exert an effect on autophagy to increase the sensitivity of tumor cells to chemotherapeutic drugs

\begin{tabular}{|c|c|c|c|}
\hline Compound & Chemotherapeutic drug & Result & Refs. \\
\hline \multirow[t]{3}{*}{ Curcumin } & Gefitinib & $\begin{array}{l}\text { Enhances the efficacy of the drug and overcomes the EGFR-TKI } \\
\text { resistance in NSCLC patients with wild-type EGFR and/or KRAS } \\
\text { mutation }\end{array}$ & [150] \\
\hline & 5-Fluorouracil & $\begin{array}{l}\text { Exerts synergistic effect with the chemotherapeutic drug by } \\
\text { impairing AMPK/ULK1-dependent autophagy }\end{array}$ & [155] \\
\hline & Docetaxel & $\begin{array}{l}\text { Leads to induction of apoptosis and autophagy through PI3K } \\
\text { AKT/mTOR pathway }\end{array}$ & [156] \\
\hline \multirow[t]{2}{*}{ Resveratrol } & Cisplatin & $\begin{array}{l}\text { Induces autophagic and apoptotic death in drug-resistant oral } \\
\text { cancer cells }\end{array}$ & [151] \\
\hline & Gefitinib & $\begin{array}{l}\text { Overcomes drug resistance while inducing apoptosis, } \\
\text { autophagy, and senescence in PC9/G NSCLC cells }\end{array}$ & [157] \\
\hline EGCG & Cisplatin & $\begin{array}{l}\text { Increases sensitivity of CAR cells, apoptosis, and autophagy by } \\
\text { AKT/STAT3 pathway }\end{array}$ & [154] \\
\hline Apigenin & Cisplatin & $\begin{array}{l}\text { Inhibits growth of drug-resistant colon cancer cells while } \\
\text { inducing autophagy }\end{array}$ & [158] \\
\hline Liquiritin & Cisplatin & $\begin{array}{l}\text { Induces apoptosis and autophagy in drug-resistant gastric } \\
\text { cancer cells }\end{array}$ & [159] \\
\hline GL-V9 & Adriamycin & $\begin{array}{l}\text { Reverses drug resistance by blocking JNK2-related protective } \\
\text { autophagy in HCC }\end{array}$ & {$[160]$} \\
\hline
\end{tabular}


to decrease the resistance to cisplatin by means of downregulating ERCC1 in non-small cell lung cancer (both in vitro and in vivo) [166].

Evidence indicated that curcumin increases the cisplatin sensitivity of lung cancer cells by inactivating ERK1/2 and reducing protein levels of ERCC1 and thymidine phosphorylase [165]. Cisplatin exerts its antitumor effects through the formation of intraand inter-strand cross-links of DNA, leading to blockade of DNA replication. Fanconi anemia (FA)/BRCA is a repair pathway for DNA cross-link damage and modulates the resistance of cells to DNA cross-link agents, such as cisplatin. In cisplatin-resistant lung adenocarcinoma (A549/DDP) cells, curcumin increases the antitumor effects of cisplatin. Furthermore, curcumin decreases the cisplatin-induced mono-ubiquitination of FANCD1 and formation of nuclear foci. This implies that curcumin-induced enhanced cisplatin sensitivity is mediated by suppression of the FA/BRCA pathway [167]. BRCA1 and RAD51 are two proteins leading to homologous recombination (HR) and thereby repair of double-strand DNA breaks [168].

Resveratrol enhances the antitumor effects of cisplatin in MCF-7 and chemo-resistant MCF-7 (MCF-7R) breast cancer cells. Data demonstrated that resveratrol at a concentration of $100 \mu \mathrm{M}$ reduces the protein levels of Rad51 and transcript levels of components of the HR initiation complex. It has been observed that following $48 \mathrm{~h}$ of DNA damage induced by cisplatin, Rad51 protein levels are increased. However, resveratrol suppresses the upregulation of Rad51. Also, resveratrol sustains the phosphorylation of histone $\mathrm{H} 2 \mathrm{AX}$ at serine 139, implying the inhibitory effect of resveratrol on the repair of double-strand breaks (DSBs) [169]. Furthermore, examinations on patient-derived glioblastoma-initiating cell lines have clarified another aspect of resveratrol's DDR-associated functions: enhancing the cytotoxicity of temozolomide through DNA doublestranded breaks/pATM/pATR/p53 pathway activation [170].

\section{Cancer stem cells}

Cancer stem cells (CSCs) are a class of tumorigenic cells that are mostly known for their self-renewal and multipotency features and make up less than $1 \%$ of the cells existing within a tumor $[171,172]$. Investigations on almost all types of cancer have revealed that CSCs are responsible for decreasing the tumor response to both chemo- and radiotherapy [173-184]. It seems that slowing down the cell cycle, having anti-apoptotic machinery, a high capacity for repairing DNA damage, the potency of establishing a proper environment for cancer growth, and stemness features are the main reasons why CSCs provide resistance to our common therapies $[171,172,185,186]$. Notch, Wnt, STAT3, PI3K/Akt, and NF-kB signaling pathways along with protective autophagy, metabolic plasticity, and oxidative modulators are some other helpers of CSCs in this process [186, 187]. Overall, targeting CSCs is a suitable approach for decreasing tumor resistance and increasing the efficacy of our common therapies.

Considering polyphenols for targeting this population of cells has recently given a new insight for treating resistant cancers. A line of research conducted on curcumin showed the anti-CSC characteristics of this agent in colon [188], pancreatic [189], liver [190], breast [50], and brain [191] cancers. Curcumin treatment administered for cancerous cells of the colon resulted in lower levels of CSC markers such as CD44, CD133, and CD24 and lower ability of CSCs to form a sphere [188]. Additionally, curcumin triggers 
apoptosis in CSCs either administered alone or with irinotecan (CPT-11) and thereby decreases resistance to this chemotherapeutic drug [188]. Decreasing the stemness features of CSCs through inhibiting the enhancer of zeste homolog-2 (EZH2) subunit of polycomb repressive complex 2 (PRC2) is also attributed to curcumin [189, 192]. Inhibiting a long non-coding RNA named PVT1 is how curcumin sensitizes pancreatic cancer cells to gemcitabine [189]. Other than that, stemness-related genes including Nanog, Sox 2 , and Oct 4 are also prone to be affected by curcumin [50]. Another mechanism by which curcumin decreases chemoresistance is its ability to decrease antiapoptotic protein levels and increase proapoptotic protein levels in CSCs [193]. The former proteins include Bcl-2 and Bcl-w and the latter ones include Bax, Bak, Bad, Bik, and Bim. In this way, the resistance of breast cancer to mitomycin C can be diminished [193]. Nanomedicine can also be effective in treating brain cancer with curcumin [191]. Curcuminloaded nanoparticles grafted with anti-aldehyde dehydrogenase not only increased the permeability of curcumin through the brain-blood barrier but also provided a steady release of this polyphenol [191]. An in vivo study conducted by Zhou et al. [194] also demonstrated that curcumin increases the sensitivity of breast cancer cells to mitomycin C. In this study, ATP-binding cassette (ABC) transporters ABCG2 and ABCC1 acted as mediators of curcumin's effects on breast cancer stem cells, which were reduced after the combinatorial treatment [194].

Epigallocatechin-3-gallate is another member of the polyphenol family which is also able to reverse some of CSC characteristics including renewal and migration in nasopharyngeal cancer cells [195]. Baicalin is a flavone whose role in EMT has been investigated on an osteosarcoma cell line: it can inhibit the EMT-inducing transcription factors Snail1 and Slug and thereby reduce the anoikis-related resistance [196]. Additionally, baicalin inhibits the PI3K/Akt/NF- $\mathrm{KB}$ pathway, which leads to EMT reversion and a decrease in cisplatin resistance of lung adenocarcinoma cells (in vivo and in vitro) [197].

An in vivo study conducted by Toden and colleagues also corroborated the anti-resistance effects of EGCG on cancer stem cells. They observed that 5FU sensitivity could be achieved when EGCG suppressed colorectal cancer stem cells through affecting the Notch signaling pathway and increasing the levels of tumor suppressive microRNAs [198].

\section{Reactive oxygen species}

Through altering the hemostasis of redox, cancer cells enhance chemoresistance. Different processes are involved in chemoresistance mediated by redox which includes increased progression of the cell cycle, autophagy mediated by endoplasmic reticulum stress, increased numbers of cancer stem-like cells, and enhanced conversion to metastasis [199]. ROS exert several functions in cancer cells, such as regulating proliferation, apoptosis, and survival. Compared to normal and non-multidrug-resistant cancer cells, ROS levels and the activity of antioxidant enzymes are increased in cancer cells that are resistant to chemotherapeutic agents. Therefore, changes in ROS levels may have a greater impact on multidrug-resistant cancer cells. Studies have shown that agents modulating the generation of ROS are potentially useful for treating patients with multidrugresistant cancer [200]. 
The thioredoxin (Trx) system has three key members which are NADPH, Trx, and thioredoxin reductase (TrxR). This system, which is involved in the regulation of redox, has been shown to play a role in the development and progression of cancer. Indeed, high expression levels of Trx and TrxR in cancer cells lead to drug resistance [201]. Ai and colleagues have designed 21 ligustrazine-curcumin hybrids (10a-u) and reported that compound 10d suppresses the proliferation in both drug-resistant and drug-sensitive lung cancer cells. It was observed that $10 \mathrm{~d}$ inhibited the $\operatorname{Tr} x / \operatorname{Tr} x R$ system while enhancing the intracellular accumulation of ROS as well as apoptosis [202]. In another study by Zhou et al. an analog of curcumin, (1E,4Z,6E)-5-hydroxy-1-(4-hydroxy-3methoxyphenyl)-7-(5-methylfuran-2-yl)hepta-1,4,6-trien-3-one (2a), suppressed the growth of cisplatin-resistant lung cancer A59 cells. Moreover, A549/CDDP cells pretreated with 2a show sensitivity to cisplatin while TrxR activity is suppressed in them. 2a consequently increases the intracellular accumulation of ROS and decreases glutathione (GSH) and the GSH/GSSG ratio, indicating the shift of intracellular redox balance to an oxidative state [203].

Nuclear factor erythroid 2-related factor 2 (NRF2) is a transcription factor that is traditionally found to regulate the protective mechanisms against oxidative stress [204]. Recent investigations have shown that this transcription factor is also involved in the development and progression of cancers as well as chemoresistance [205-210]. Therefore, NRF2 is reported to be a potential candidate in overcoming cancer chemoresistance [211]. Zhang et al. [212] reported that curcumin induces the deficiency of Nrf2, which, in turn, changes the ratio of Bcl-2 associated X protein/Bcl-2 expression. Consequently, curcumin treatment results in apoptosis induction in HCT-8/5-Fu cells and reverses the multidrug resistance in colorectal cancer cells. Curcumin also chemosensitizes head and neck squamous carcinoma cells to cisplatin in vitro through targeting Nrf-2 and pSTAT3 signaling pathways [213]. In pancreatic cancer cells, resveratrol inhibits the nutrientdeprivation autophagy factor-1 (NAF-1) via activating the Nrf2 pathway and accumulating intracellular ROS [214]. Expression levels of Nrf2 as well as NADPH and heme oxygenase-1, target proteins of Nrf2, are higher in tamoxifen-resistant MCF-7 (MCF-7/ TAM) cells compared to MCF-7 cells. EGCG is reported to significantly increases the sensitivity of MCF-7/TAM cells to tamoxifen while decreasing the mRNA and protein levels of Nrf2. Using siRNA of Nrf2 reverses the tamoxifen resistance in MCF-7/TAM cells. Furthermore, combined treatment with EGCG and Nrf2 siRNA results in a synergic Nrf2 downregulation and reversal of tamoxifen resistance [215].

The expression of androgen receptor (AR) is significantly associated with poor prognosis of glioblastoma patients [216]. Moreover, AR leads to the development of resistance against temozolomide. The curcumin analog ALZ003 is able to induce ubiquitination of AR by FBXL2, resulting in its degradation. ALZ003 suppresses the survival of both temozolomide-sensitive and -resistant glioblastoma cells in vitro and in vivo. Treating glioblastoma cells with ALZ003 also leads to lipid peroxidation, ROS accumulation, and inhibition of glutathione peroxidase (GPX) 4, which are indicators of ferroptosis. Regarding the in vivo effect of this treatment, Chen and colleagues transplanted temozolomide-sensitive or -resistant glioblastoma U87MG cells into mouse brain. They observed that ALZ003 suppressed the proliferation of tumor cells as well as increasing their survival [216] (Table 2). 
Table 2 Modulating ROS to overcome cancer drug resistance

\begin{tabular}{|c|c|c|c|}
\hline Mode of action & Compound & Application & Refs. \\
\hline \multirow[t]{2}{*}{ TrxR } & $2 \mathrm{a}$, curcumin analog ${ }^{\mathrm{a}}$ & Sensitizes A549 cells to cisplatin & [203] \\
\hline & $10 d^{b}$ & $\begin{array}{l}\text { Effective on drug-sensitive (A549, SPC-A-1, LTEP-G-2) and } \\
\text { drug-resistant (A549/DDP) lung cancer cells }\end{array}$ & [202] \\
\hline \multirow[t]{4}{*}{ Nrf2 } & Curcumin & $\begin{array}{l}\text { Mediates cisplatin chemoresistance in head and neck } \\
\text { squamous cell carcinoma }\end{array}$ & [213] \\
\hline & & $\begin{array}{l}\text { Reverses multidrug resistance in the HCT-8/5-Fu human } \\
\text { colorectal cancer }\end{array}$ & [212] \\
\hline & Resveratrol & $\begin{array}{l}\text { Enhances the sensitivity of pancreatic cancer cells to } \\
\text { gemcitabine }\end{array}$ & {$[214]$} \\
\hline & Chrysin & $\begin{array}{l}\text { Reduces doxorubicin resistance by down-regulating Nrf2 } \\
\text { signaling pathway in BEL-7402/ADM cells }\end{array}$ & {$[217]$} \\
\hline GPX & ALZ003, curcumin analog & Suppresses growth of temozolomide-resistant glioblastoma & [216] \\
\hline
\end{tabular}

a (1E,4Z,6E)-5-hydroxy-1-(4-hydroxy-3-methoxyphenyl)-7-(5-methylfuran-2-yl)hepta-1,4,6-trien-3-one (2a)

${ }^{\mathrm{b}}$ Active compound of 21 ligustrazine-curcumin hybrids (10a-u)

\section{Epithelial to mesenchymal transition}

Epithelial to mesenchymal transition or EMT is a dedifferentiation process whose target is to prepare epithelial cells for migration and metastasis [186]. Diverse molecular alterations cause the transformation of polar epithelial cells into multipolar and motile mesenchymal cells [218]; therefore, epithelial genes containing E-cadherin, ZO-1, and occludin should be decreased in cells undergoing EMT while mesenchymal genes containing $\mathrm{N}$-cadherin, vimentin, and fibronectin ought to be increased [218]. Similar to every other cellular process, signaling pathways have a pivotal role in EMT; these pathways encompass transforming growth factor beta (TGF $\beta$ ), Wnt, Notch and Hedgehog [219]. The mechanism by which EMT contributes to the resistance of several cancer types is mainly related to CSCs [220]. This association was suggested due to the similarity of signaling pathways involved in EMT and CSCs. To our knowledge, CSCs probably recall EMT by affecting the non-CSC cells of the tumor [186]. The ATP-binding cassette (ABC) transporters seem to be greatly involved in CSC-induced EMT of tumor cells. Investigations on resistant tumor cells undergoing EMT reveal the higher expression of these transporters [221]. As well as CSCs, EMT is also susceptible to the ingredients of the tumor microenvironment including cancer-associated fibroblasts (CAF) and hypoxia [220, 222].

For targeting EMT in cancer cells, curcumin is confirmed to be a suitable option. It decreases 5-fluorouracil-resistance by means of affecting the TET1-NKD2-WNT axis and thereby hindering EMT [223]. MicroRNAs are other mediators of curcumin's effects; miR-200b, miR-200c, miR-141, miR-429, and miR-101 are anti-EMT miRNAs that are upregulated after curcumin treatment [192]. In colorectal cancer cells, this effect aids the reduction of 5-fluorouracil resistance [192]. Furthermore, in colorectal cancer calls, curcumin increases the markers of epithelial cells including E-cadherin when utilized with irinotecan [224]. Regulating the TGF- $\beta / \mathrm{Smad} 2 / 3$ signaling pathway for decreasing the resistance to oxaliplatin through EMT inhibition is another mechanism of curcumin's actions in colorectal cancer cells [225]. H19 is a long noncoding RNA with the role of establishing tamoxifen resistance in breast cancer cells, 
which can be impacted by curcumin [226]. H19 overexpression is responsible for EMT in breast cancer cells, which can be reversed after curcumin treatment [226].

In addition to curcumin, resveratrol might also be a suitable option for overcoming resistance through EMT inhibition [227]. A variety of ways have been revealed for resveratrol to affect EMT: "reactivating p53 and inducing miR-145 and miR-200c" [228], modulating the connection between SIRT1 and $\beta$-catenin [229], and modulating the PTEN/Akt signaling pathway [230]. EMT inhibition is also possible by quercetin. Quercetin decreases the resistance to docetaxel in prostate cancer cells by affecting some mechanisms including EMT [231]. NF-kB p65 inactivation is another mechanism that is used by epigallocatechin-3-gallate to inhibit EMT in nasopharyngeal cancer stem cells [195]. EGCG, which is a green tea polyphenol, seems to be effective against CSCs of nasopharyngeal carcinoma and inhibits some of their features including EMT [232]. Lin et al. [232] demonstrated this effect by measuring EMT markers such as Snail, vimentin, and E-cadherin after EGCG treatment. Geraniin is another member of the polyphenol family which can be found in Phyllanthus amarus [233]. Elevating the levels of E-cadherin and decreasing the levels of Snail are two effects of this agent on lung cancer cells. After using geraniin, anoikis resistance is decreased in these cells through inhibition of EMT [233].

\section{Conclusions}

Our knowledge of the anti-cancer effects of polyphenols has remarkably expanded since the discovery of these beneficial agents, which is why the understanding of the underlying mechanisms by which they work is essential. Accumulative investigations have clarified how these natural compounds are able to inhibit cancer hallmarks such as proliferation, apoptosis, inflammation, etc. But what if polyphenols have a more significant ability that would assist us through overcoming cancer? Resistance to the common therapies involving chemo- and radiotherapy is our most important difficulty in restricting the progression of cancer cells and decreasing the number of cancer-related deaths. In this regard, we have taken a look at the polyphenols' mechanisms of action which are specific to overcoming the resistance of different cancers (summarized in Fig. 3). According to the discussed studies, affecting the gene expression and signaling pathways associated with cancer stem cells is an important aspect of polyphenols' effects which makes them capable of inhibiting EMT, oxidative stress, and other stemness features to reduce the resistance. Increasing drug uptake by tumor cells, decreasing drug metabolism by enzymes (e.g. cytochromes and glutathione-S-transferases), and reducing drug efflux are some of the mechanisms by which polyphenols increase the sensitivity of cancer cells to chemotherapeutic agents. Polyphenols also affect other targets for overcoming chemoresistance in cancer cells, including cell death (i.e. autophagy and apoptosis), EMT, ROS, DNA repair processes, cancer stem cells, and epigenetics (e.g. miRNAs). So far, only a few clinical trials have been performed on the role of polyphenols in overcoming cancer drug resistance. One of them is a phase II study of resveratrol (SRT501) with bortezomib in patients with relapse of refractory multiple myeloma. This study has shown that this therapeutic approach has a low safety profile while showing minimal efficacy [234]. Another clinical trial is a phase I/II study of curcumin and gemcitabine in patients 


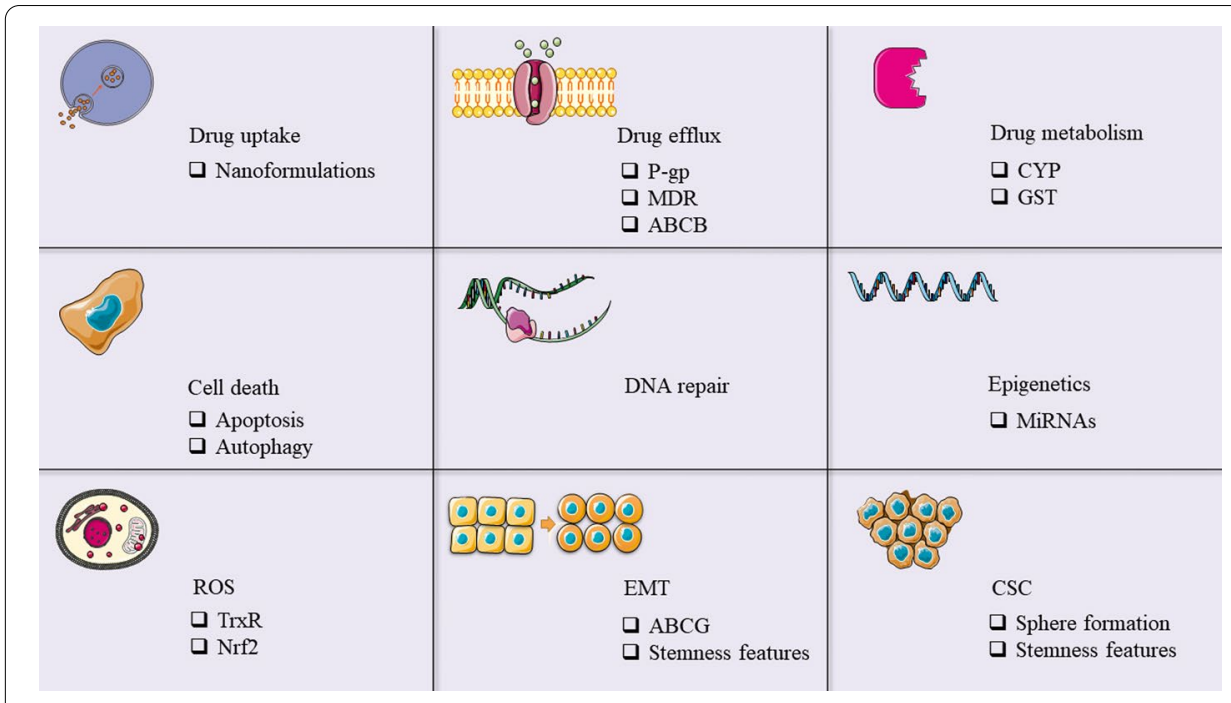

Fig. 3 Mechanisms involved in cancer drug resistance in which polyphenols may play a role

with gemcitabine-resistant pancreatic cancer. This study, performed on 21 patients, shows that combined therapy with gemcitabine and $8 \mathrm{~g}$ of oral curcumin daily is a safe and feasible treatment for patients and further investigations should be carried out to define its efficacy [235]. Taken together, the developments in our understanding of these agents have revealed the wide range of their effects against treatment resistance, but still, the lack of sufficient human research is holding us back from using polyphenols widely in clinical practice.

\section{Abbreviations}

EGCG: Epigallocatechin gallate; miRNA: MicroRNA; DOX: Doxorubicin; AML: Acute myeloid leukemia; p-gp: P-glycoprotein; ABC: ATP-binding cassette; MRP1: Multidrug resistance protein 1; BCRP: Breast cancer resistant protein; 5-FU: 5-Fluorouracil; ABCB4: ATP binding cassette subfamily B member 4; GGTs: Gamma-glutamyl transferases; TPMTs: Thiopurine methyltransferases; GSTs: Glutathione-S-transferases; DPDs: Dihydropyrimidine dehydrogenases; UGTs: Uridine diphospho-glucuronosyltransferases; GGTP: Gamma-glutamyl transpeptidase; TKI: Tyrosine kinase inhibitor; EGFR: Epidermal growth factor receptor; NSCLC: Non-small-cell lung cancer; MTX: Methotrexate; MDR1: Multidrug resistance 1.

\section{Acknowledgements}

Not applicable.

\section{Authors' contributions}

FS, PM-D, ZA and BY contributed to the conception, design and drafting of the manuscript. All authors read and approved the final manuscript.

Funding

Not applicable.

Availability of data and materials

Not applicable.

\section{Declarations}

Ethics approval and consent to participate

Not applicable.

\section{Consent for publication}

Not applicable.

Competing interests

The authors declare no conflict of interest. 


\begin{abstract}
Author details
${ }^{1}$ Research Center for Biochemistry and Nutrition in Metabolic Diseases, Institute for Basic Sciences, Kashan University of Medical Sciences, Kashan, Islamic Republic of Iran. ${ }^{2}$ Molecular Medicine Research Center, Tabriz University of Medical Sciences, Tabriz, Iran. ${ }^{3}$ Department of Biochemistry, Faculty of Medicine, Tabriz University of Medical Sciences, Tabriz, Iran.
\end{abstract}

Received: 17 September 2021 Accepted: 17 December 2021

Published online: 03 January 2022

\title{
References
}

1. Elshimali YI, Wu Y, Khaddour H, Wu Y, Gradinaru D, Sukhija H, et al. Optimization of cancer treatment through overcoming drug resistance. J Cancer Res Oncobiol. 2018;1 (2).

2. Nikolaou M, Pavlopoulou A, Georgakilas AG, Kyrodimos E. The challenge of drug resistance in cancer treatment: a current overview. Clin Exp Metas. 2018;35(4):309-18.

3. Du M, Ouyang Y, Meng F, Ma Q, Liu H, Zhuang Y, et al. Nanotargeted agents: an emerging therapeutic strategy for breast cancer. Nanomedicine. 2019;14(13):1771-86.

4. Holohan C, Van Schaeybroeck S, Longley DB, Johnston PG. Cancer drug resistance: an evolving paradigm. Nat Rev Cancer. 2013;13(10):714-26.

5. Wu G, Wilson G, George J, Liddle C, Hebbard L, Qiao L. Overcoming treatment resistance in cancer: current understanding and tactics. Cancer Lett. 2017;387:69-76.

6. Gottesman MM. Mechanisms of cancer drug resistance. Annu Rev Med. 2002;53:615-27.

7. Alisi A, Cho WC, Locatelli F, Fruci D. Multidrug resistance and cancer stem cells in neuroblastoma and hepatoblastoma. Int J Mol Sci. 2013;14(12):24706-25.

8. Fiaschi T, Chiarugi P. Oxidative stress, tumor microenvironment, and metabolic reprogramming: a diabolic liaison. Int J Cell Biol. 2012;2012:762825.

9. Khalili-Tanha G, Moghbeli M. Long non-coding RNAs as the critical regulators of doxorubicin resistance in tumor cells. Cell Mol Biol Lett. 2021;26(1):39.

10. Perron NR, Brumaghim JL. A review of the antioxidant mechanisms of polyphenol compounds related to iron binding. Cell Biochem Biophys. 2009;53(2):75-100.

11. Li AN, Li S, Zhang YJ, Xu XR, Chen YM, Li HB. Resources and biological activities of natural polyphenols. Nutrients. 2014;6(12):6020-47.

12. Brglez Mojzer E, Knez Hrnčič M, Škerget M, Knez Ž, Bren U. Polyphenols: extraction methods, antioxidative action, bioavailability and anticarcinogenic effects. Molecules (Basel, Switzerland). 2016;21(7):901.

13. Arranz S, Chiva-Blanch G, Valderas-Martínez P, Medina-Remón A, Lamuela-Raventós RM, Estruch R. Wine, beer, alcohol and polyphenols on cardiovascular disease and cancer. Nutrients. 2012;4(7):759-81.

14. August DA, Landau J, Caputo D, Hong J, Lee MJ, Yang CS. Ingestion of green tea rapidly decreases prostaglandin E2 levels in rectal mucosa in humans. Cancer Epidemiol Biomark Prevent Publ Am Assoc Cancer Res Cospons Am Soc Prevent Oncol. 1999:8(8):709-13.

15. Benzie IF, Szeto YT, Strain JJ, Tomlinson B. Consumption of green tea causes rapid increase in plasma antioxidant power in humans. Nutr Cancer. 1999:34(1):83-7.

16. Kruk J, Aboul-Enein YH. Reactive oxygen and nitrogen species in carcinogenesis: implications of oxidative stress on the progression and development of several cancer types. Mini Rev Med Chem. 2017:17(11):904-19.

17. Heim KE, Tagliaferro AR, Bobilya DJ. Flavonoid antioxidants: chemistry, metabolism and structure-activity relationships.J Nutr Biochem. 2002:13(10):572-84.

18. Burda S, Oleszek W. Antioxidant and antiradical activities of flavonoids. J Agric Food Chem. 2001;49(6):2774-9.

19. Nagao A, Seki M, Kobayashi H. Inhibition of xanthine oxidase by flavonoids. Biosci Biotechnol Biochem. 1999;63(10):1787-90.

20. Nijveldt RJ, van Nood E, van Hoorn DE, Boelens PG, van Norren K, van Leeuwen PA. Flavonoids: a review of probable mechanisms of action and potential applications. Am J Clin Nutr. 2001;74(4):418-25.

21. Tada Y, Suzuki J. Oxidative stress and myocarditis. Curr Pharm Des. 2016;22(4):450-71.

22. Iio M, Ono Y, Kai S, Fukumoto M. Effects of flavonoids on xanthine oxidation as well as on cytochrome $\mathrm{c}$ reduction by milk xanthine oxidase. J Nutr Sci Vitaminol. 1986;32(6):635-42.

23. Vanacker SA, Tromp MN, Haenen GR, Vandervijgh W, Bast A. Flavonoids as scavengers of nitric oxide radical. Biochem Biophys Res Commun. 1995;214(3):755-9.

24. Hider RC, Liu ZD, Khodr HH. Metal chelation of polyphenols. Methods Enzymol. 2001:335:190-203.

25. Yoshino M, Murakami K. Interaction of iron with polyphenolic compounds: application to antioxidant characterization. Anal Biochem. 1998;257(1):40-4.

26. Morel I, Lescoat G, Cogrel P, Sergent O, Pasdeloup N, Brissot P, et al. Antioxidant and iron-chelating activities of the flavonoids catechin, quercetin and diosmetin on iron-loaded rat hepatocyte cultures. Biochem Pharmacol. 1993:45(1):13-9.

27. Ferrali M, Signorini C, Caciotti B, Sugherini L, Ciccoli L, Giachetti D, et al. Protection against oxidative damage of erythrocyte membrane by the flavonoid quercetin and its relation to iron chelating activity. FEBS Lett. 1997:416(2):123-9.

28. Sestili P, Diamantini G, Bedini A, Cerioni L, Tommasini I, Tarzia G, et al. Plant-derived phenolic compounds prevent the DNA single-strand breakage and cytotoxicity induced by tert-butylhydroperoxide via an iron-chelating mechanism. Biochem J. 2002:364(Pt 1):121-8

29. Yao $Q$, Lin M, Wang Y, Lai Y, Hu J, Fu T, et al. Curcumin induces the apoptosis of A549 cells via oxidative stress and MAPK signaling pathways. Int J Mol Med. 2015;36(4):1118-26. 
30. Zhang L, Cheng X, Xu S, Bao J, Yu H. Curcumin induces endoplasmic reticulum stress-associated apoptosis in human papillary thyroid carcinoma BCPAP cells via disruption of intracellular calcium homeostasis. Medicine. 2018;97(24):e11095.

31. Mou S, Zhou Z, He Y, Liu F, Gong L. Curcumin inhibits cell proliferation and promotes apoptosis of laryngeal cancer cells through BCl-2 and PI3K/Akt, and by upregulating miR-15a. Oncol Lett. 2017;14(4):4937-42.

32. He ZY, Shi CB, Wen H, Li FL, Wang BL, Wang J. Upregulation of p53 expression in patients with colorectal cancer by administration of curcumin. Cancer Invest. 2011;29(3):208-13.

33. Sadoughi F, Dana PM, Asemi Z, Yousefi B. Targeting microRNAs by curcumin: implication for cancer therapy. Crit Rev Food Sci Nutr. 2021:1-12.

34. Hu S, Xu Y, Meng L, Huang L, Sun H. Curcumin inhibits proliferation and promotes apoptosis of breast cancer cells. Exp Ther Med. 2018;16(2):1266-72.

35. Zhou C, Ding J, Wu Y. Resveratrol induces apoptosis of bladder cancer cells via miR-21 regulation of the Akt/Bcl-2 signaling pathway. Mol Med Rep. 2014;9(4):1467-73.

36. Singh SK, Banerjee S, Acosta EP, Lillard JW, Singh R. Resveratrol induces cell cycle arrest and apoptosis with docetaxel in prostate cancer cells via a p53/ p21WAF1/CIP1 and p27KIP1 pathway. Oncotarget. 2017;8(10):17216-28.

37. Ji K, Sun X, Liu Y, Du L, Wang Y, He N, et al. Regulation of apoptosis and radiation sensitization in lung cancer cells via the Sirt1/NF-KB/Smac pathway. Cell Physiol Biochem Int J Exp Cell Physiol Biochem Pharmacol. 2018;48(1):304-16.

38. Liu Y, Tong L, Luo Y, Li X, Chen G, Wang Y. Resveratrol inhibits the proliferation and induces the apoptosis in ovarian cancer cells via inhibiting glycolysis and targeting AMPK/mTOR signaling pathway. J Cell Biochem. 2018;119(7):6162-72.

39. Pawlowska E, Szczepanska J, Szatkowska M, Blasiak J. An interplay between senescence, apoptosis and autophagy in glioblastoma multiforme-role in pathogenesis and therapeutic perspective. Int J Mol Sci. 2018;19(3):889.

40. Wu H, Chen L, Zhu F, Han X, Sun L, Chen K. The cytotoxicity effect of resveratrol: cell cycle arrest and induced apoptosis of breast cancer 4T1 cells. Toxins. 2019;11(12):731.

41. Yousef M, Vlachogiannis IA, Tsiani E. Effects of resveratrol against lung cancer: in vitro and in vivo studies. Nutrients. 2017;9(11):1231.

42. Honari M, Shafabakhsh R, Reiter RJ, Mirzaei H, Asemi Z. Resveratrol is a promising agent for colorectal cancer prevention and treatment: focus on molecular mechanisms. Cancer Cell Int. 2019;19:180.

43. Yoshimura H, Yoshida H, Matsuda S, Ryoke T, Ohta K, Ohmori M, et al. The therapeutic potential of epigallocatechin-3-gallate against human oral squamous cell carcinoma through inhibition of cell proliferation and induction of apoptosis: In vitro and in vivo murine xenograft study. Mol Med Rep. 2019;20(2):1139-48.

44. He YC, He L, Khoshaba R, Lu FG, Cai C, Zhou FL, et al. Curcumin nicotinate selectively induces cancer cell apoptosis and cycle arrest through a P53-mediated mechanism. Molecules (Basel, Switzerland). 2019;24(22):4179.

45. Kabała-Dzik A, Rzepecka-Stojko A, Kubina R, Iriti M, Wojtyczka RD, Buszman E, et al. Flavonoids, bioactive components of propolis, exhibit cytotoxic activity and induce cell cycle arrest and apoptosis in human breast cancer cells MDA-MB-231 and MCF-7—a comparative study. Cell Mol Biol (Noisy-le-Grand, France). 2018;64(8):1-10.

46. Suhail Y, Cain MP, Vanaja K, Kurywchak PA, Levchenko A, Kalluri R, et al. Systems biology of cancer metastasis. Cell Syst. 2019;9(2):109-27.

47. Hao Y, Baker D, Ten Dijke P. TGF- $\beta$-mediated epithelial-mesenchymal transition and cancer metastasis. Int J Mol Sci. 2019;20(11):2767.

48. Quail DF, Joyce JA. Microenvironmental regulation of tumor progression and metastasis. Nat Med. 2013;19(11):1423-37.

49. Zeeshan R, Mutahir Z. Cancer metastasis_tricks of the trade. Bosn J Basic Med Sci. 2017:17(3):172-82.

50. Hu C, Li M, Guo T, Wang S, Huang W, Yang K, et al. Anti-metastasis activity of curcumin against breast cancer via the inhibition of stem cell-like properties and EMT. Phytomed Int J Phytothera Phytopharmacol. 2019:58:152740.

51. Yu D, Ye T, Xiang Y, Shi Z, Zhang J, Lou B, et al. Quercetin inhibits epithelial-mesenchymal transition, decreases invasiveness and metastasis, and reverses IL-6 induced epithelial-mesenchymal transition, expression of MMP by inhibiting STAT3 signaling in pancreatic cancer cells. Onco Targets Ther. 2017;10:4719-29.

52. Hoca M, Becer E, Kabadayı H, Yücecan S, Vatansever HS. The effect of resveratrol and quercetin on epithelial-mesenchymal transition in pancreatic cancer stem cell. Nutr Cancer. 2020;72(7):1231-42.

53. Dong Y, Yang J, Yang L, Li P. Quercetin inhibits the proliferation and metastasis of human non-small cell lung cancer cell line: the key role of Src-mediated fibroblast growth factor-inducible 14 (Fn14)/nuclear factor kappa B (NF-kB) pathway. Med Sci Monit Int Med J Exp Clin Res. 2020;26:e920537.

54. Lee YH, Tuyet PT. Synthesis and biological evaluation of quercetin-zinc (II) complex for anti-cancer and anti-metastasis of human bladder cancer cells. In Vitro Cell Dev Biol Anim. 2019;55(6):395-404.

55. Shafabakhsh R, Asemi Z. Quercetin: a natural compound for ovarian cancer treatment. J Ovarian Res. 2019;12(1):55.

56. Sun Y, Zhou QM, Lu YY, Zhang H, Chen QL, Zhao M, et al. Resveratrol inhibits the migration and metastasis of MDAMB-231 human breast cancer by reversing TGF- $\beta 1$-induced epithelial-mesenchymal transition. Molecules (Basel, Switzerland). 2019;24(6):1131.

57. Yuan L, Zhou M, Huang D, Wasan HS, Zhang K, Sun L, et al. Resveratrol inhibits the invasion and metastasis of colon cancer through reversal of epithelial-mesenchymal transition via the AKT/GSK-3 $3 /$ Snail signaling pathway. Mol Med Rep. 2019;20(3):2783-95.

58. Ponnusamy L, Mahalingaiah PKS, Singh KP. Epigenetic reprogramming and potential application of epigeneticmodifying drugs in acquired chemotherapeutic resistance. Adv Clin Chem. 2020;94:219-59.

59. Xu WS, Parmigiani RB, Marks PA. Histone deacetylase inhibitors: molecular mechanisms of action. Oncogene. 2007;26(37):5541-52.

60. Liu HL, Chen Y, Cui GH, Zhou JF. Curcumin, a potent anti-tumor reagent, is a novel histone deacetylase inhibitor regulating B-NHL cell line Raji proliferation. Acta Pharmacol Sin. 2005;26(5):603-9. 
61. Chen Y, Shu W, Chen W, Wu Q, Liu H, Cui G. Curcumin, both histone deacetylase and p300/CBP-specific inhibitor, represses the activity of nuclear factor kappa B and Notch 1 in Raji cells. Basic Clin Pharmacol Toxicol. 2007;101(6):427-33.

62. Lee SJ, Krauthauser C, Maduskuie V, Fawcett PT, Olson JM, Rajasekaran SA. Curcumin-induced HDAC inhibition and attenuation of medulloblastoma growth in vitro and in vivo. BMC Cancer. 2011;11:144.

63. Meja KK, Rajendrasozhan S, Adenuga D, Biswas SK, Sundar IK, Spooner G, et al. Curcumin restores corticosteroid function in monocytes exposed to oxidants by maintaining HDAC2. Am J Respir Cell Mol Biol. 2008;39(3):312-23.

64. Liu L, Fu Y, Zheng Y, Ma M, Wang C. Curcumin inhibits proteasome activity in triple-negative breast cancer cells through regulating p300/miR-142-3p/PSMB5 axis. Phytomed Int J Phytothera Phytopharmacol. 2020:78:153312.

65. Sen GS, Mohanty S, Hossain DMS, Bhattacharyya S, Banerjee S, Chakraborty J, et al. Curcumin enhances the efficacy of chemotherapy by tailoring p65NFkB-p300 cross-talk in favor of p53-p300 in breast cancer. J Biol Chem. 2011;286(49):42232-47.

66. Liu YL, Yang HP, Gong L, Tang CL, Wang HJ. Hypomethylation effects of curcumin, demethoxycurcumin and bisdemethoxycurcumin on WIF-1 promoter in non-small cell lung cancer cell lines. Mol Med Rep. 2011;4(4):675-9.

67. Parashar G, Parashar NC, Capalash N. Curcumin causes promoter hypomethylation and increased expression of FANCF gene in SiHa cell line. Mol Cell Biochem. 2012;365(1-2):29-35.

68. Khor TO, Huang Y, Wu TY, Shu L, Lee J, Kong AN. Pharmacodynamics of curcumin as DNA hypomethylation agent in restoring the expression of Nrf2 via promoter CpGs demethylation. Biochem Pharmacol. 2011;82(9):1073-8.

69. Shu L, Khor TO, Lee JH, Boyanapalli SS, Huang Y, Wu TY, et al. Epigenetic CpG demethylation of the promoter and reactivation of the expression of Neurog 1 by curcumin in prostate LNCaP cells. AAPS J. 2011;13(4):606-14.

70. Jha AK, Nikbakht M, Parashar G, Shrivastava A, Capalash N, Kaur J. Reversal of hypermethylation and reactivation of the RARß2 gene by natural compounds in cervical cancer cell lines. Folia Biol. 2010;56(5):195-200.

71. Abusnina A, Keravis T, Yougbaré I, Bronner C, Lugnier C. Anti-proliferative effect of curcumin on melanoma cells is mediated by PDE1A inhibition that regulates the epigenetic integrator UHRF1. Mol Nutr Food Res. 2011;55(11):1677-89.

72. Du L, Xie Z, Wu LC, Chiu M, Lin J, Chan KK, et al. Reactivation of RASSF1A in breast cancer cells by curcumin. Nutr Cancer. 2012;64(8):1228-35.

73. Sadoughi F, Maleki Dana P, Asemi Z, Yousefi B. Targeting microRNAs by curcumin: implication for cancer therapy. Crit Rev Food Sci Nutr. 2021:1-12.

74. Hassan FU, Rehman MS, Khan MS, Ali MA, Javed A, Nawaz A, et al. Curcumin as an alternative epigenetic modulator: mechanism of action and potential effects. Front Genet. 2019;10:514.

75. Michaille JJ, Piurowski V, Rigot B, Kelani H, Fortman EC, Tili E. MiR-663, a MicroRNA linked with inflammation and cancer that is under the influence of resveratrol. Medicines (Basel, Switzerland). 2018;5(3):74.

76. Dhar S, Hicks C, Levenson AS. Resveratrol and prostate cancer: promising role for microRNAs. Mol Nutr Food Res. 2011;55(8):1219-29.

77. Zhang W, Jiang H, Chen Y, Ren F. Resveratrol chemosensitizes adriamycin-resistant breast cancer cells by modulating miR-122-5p. J Cell Biochem. 2019;120(9):16283-92.

78. Fu J, Shrivastava A, Shrivastava SK, Srivastava RK, Shankar S. Triacetyl resveratrol upregulates miRNA-200 and suppresses the Shh pathway in pancreatic cancer: a potential therapeutic agent. Int J Oncol. 2019;54(4):1306-16.

79. Zhao J, Fang Z, Zha Z, Sun Q, Wang H, Sun $M$, et al. Quercetin inhibits cell viability, migration and invasion by regulating miR-16/HOXA10 axis in oral cancer. Eur J Pharmacol. 2019;847:11-8.

80. Zhang C, Hao Y, Sun Y, Liu P. Quercetin suppresses the tumorigenesis of oral squamous cell carcinoma by regulating microRNA-22/WNT1/ $\beta$-catenin axis. J Pharmacol Sci. 2019;140(2):128-36.

81. Nwaeburu CC, Abukiwan A, Zhao Z, Herr I. Quercetin-induced miR-200b-3p regulates the mode of self-renewing divisions in pancreatic cancer. Mol Cancer. 2017;16(1):23.

82. Tao SF, He HF, Chen Q. Quercetin inhibits proliferation and invasion acts by up-regulating miR-146a in human breast cancer cells. Mol Cell Biochem. 2015;402(1-2):93-100.

83. Bhardwaj V, Mandal AKA. Next-generation sequencing reveals the role of epigallocatechin-3-gallate in regulating putative novel and known microRNAs which target the MAPK pathway in non-small-cell lung cancer A549 cells. Molecules (Basel, Switzerland). 2019;24(2):368.

84. Ahmed F, ljaz B, Ahmad Z, Farooq N, Sarwar MB, Husnain T. Modification of miRNA Expression through plant extracts and compounds against breast cancer: mechanism and translational significance. Phytomed Int J Phytothera Phytopharmacol. 2020;68:153168.

85. Juliano RL, Ling V. A surface glycoprotein modulating drug permeability in Chinese hamster ovary cell mutants. Biochem Biophys Acta. 1976;455(1):152-62.

86. Mansoori B, Mohammadi A, Davudian S, Shirjang S, Baradaran B. The different mechanisms of cancer drug resistance: a brief review. Adv Pharmaceut Bull. 2017;7(3):339-48.

87. Croop JM, Raymond M, Haber D, Devault A, Arceci RJ, Gros P, et al. The three mouse multidrug resistance (mdr) genes are expressed in a tissue-specific manner in normal mouse tissues. Mol Cell Biol. 1989;9(3):1346-50.

88. Muley H, Fadó R, Rodríguez-Rodríguez R, Casals N. Drug uptake-based chemoresistance in breast cancer treatment. Biochem Pharmacol. 2020;177:113959.

89. Tsai LC, Hsieh HY, Lu KY, Wang SY, Mi FL. EGCG/gelatin-doxorubicin gold nanoparticles enhance therapeutic efficacy of doxorubicin for prostate cancer treatment. Nanomedicine (Lond). 2016;11(1):9-30.

90. Viator JA, Gupta S, Goldschmidt BS, Bhattacharyyal K, Kannan R, Shukla R, et al. Gold nanoparticle mediated detection of prostate cancer cells using photoacoustic flowmetry with optical reflectance. J Biomed Nanotechnol. 2010:6(2):187-91.

91. Shukla R, Chanda N, Zambre A, Upendran A, Katti K, Kulkarni RR, et al. Laminin receptor specific therapeutic gold nanoparticles (198AuNP-EGCg) show efficacy in treating prostate cancer. Proc Natl Acad Sci USA. 2012;109(31):12426-31. 
92. Chavva SR, Deshmukh SK, Kanchanapally R, Tyagi N, Coym JW, Singh AP, et al. Epigallocatechin gallate-gold nanoparticles exhibit superior antitumor activity compared to conventional gold nanoparticles: potential synergistic interactions. Nanomaterials (Basel, Switzerland). 2019;9(3):396.

93. Kilari D, Guancial E, Kim ES. Role of copper transporters in platinum resistance. World J Clin Oncol. 2016;7(1):106-13.

94. Wang $X$, Jiang $P$, Wang $P$, Yang CS, Wang $X$, Feng Q. EGCG enhances cisplatin sensitivity by regulating expression of the copper and cisplatin influx transporter CTR1 in ovary cancer. PLoS ONE. 2015;10(4):e0125402.

95. Jiang P, Wu X, Wang X, Huang W, Feng Q. NEAT1 upregulates EGCG-induced CTR1 to enhance cisplatin sensitivity in lung cancer cells. Oncotarget. 2016;7(28):43337-51.

96. Peterson BG, Tan KW, Osa-Andrews B, Iram SH. High-content screening of clinically tested anticancer drugs identifies novel inhibitors of human MRP1 (ABCC1). Pharmacol Res. 2017;119:313-26.

97. Kweon SH, Song JH, Kim TS. Resveratrol-mediated reversal of doxorubicin resistance in acute myeloid leukemia cells via downregulation of MRP1 expression. Biochem Biophys Res Commun. 2010;395(1):104-10.

98. Li W, Zhang H, Assaraf YG, Zhao K, Xu X, Xie J, et al. Overcoming ABC transporter-mediated multidrug resistance: molecular mechanisms and novel therapeutic drug strategies. Drug Resist Updates Rev Comment Antimicrob Anticancer Chemothera. 2016;27:14-29.

99. Kawabata S, Oka M, Shiozawa K, Tsukamoto K, Nakatomi K, Soda H, et al. Breast cancer resistance protein directly confers SN-38 resistance of lung cancer cells. Biochem Biophys Res Commun. 2001;280(5):1216-23.

100. Bram EE, Ifergan I, Grimberg M, Lemke K, Skladanowski A, Assaraf YG. C421 allele-specific ABCG2 gene amplification confers resistance to the antitumor triazoloacridone C-1305 in human lung cancer cells. Biochem Pharmacol. 2007;74(1):41-53.

101. Bram EE, Stark M, Raz S, Assaraf YG. Chemotherapeutic drug-induced ABCG2 promoter demethylation as a novel mechanism of acquired multidrug resistance. Neoplasia (New York, NY). 2009;11(12):1359-70.

102. Müller M, de Vries EG, Jansen PL. Role of multidrug resistance protein (MRP) in glutathione S-conjugate transport in mammalian cells. J Hepatol. 1996;24(Suppl 1):100-8.

103. Waghray D, Zhang Q. Inhibit or evade multidrug resistance P-glycoprotein in cancer treatment. J Med Chem. 2018;61(12):5108-21.

104. Abraham J, Salama NN, Azab AK. The role of P-glycoprotein in drug resistance in multiple myeloma. Leuk Lymphoma. 2015;56(1):26-33.

105. Khaleel SA, Al-Abd AM, Ali AA, Abdel-Naim AB. Didox and resveratrol sensitize colorectal cancer cells to doxorubicin via activating apoptosis and ameliorating P-glycoprotein activity. Sci Rep. 2016;6:36855.

106. Qian F, Wei D, Zhang Q, Yang S. Modulation of P-glycoprotein function and reversal of multidrug resistance by (-)-epigallocatechin gallate in human cancer cells. Biomed Pharmacothera. 2005;59(3):64-9.

107. Liang G, Tang A, Lin X, Li L, Zhang S, Huang Z, et al. Green tea catechins augment the antitumor activity of doxorubicin in an in vivo mouse model for chemoresistant liver cancer. Int J Oncol. 2010;37(1):111-23.

108. Wang L, Jin F, Qin A, Hao Y, Dong Y, Ge S, et al. Targeting Notch1 signaling pathway positively affects the sensitivity of osteosarcoma to cisplatin by regulating the expression and/or activity of Caspase family. Mol Cancer. 2014;13:139.

109. Wang L, Wang C, Jia Y, Liu Z, Shu X, Liu K. Resveratrol increases anti-proliferative activity of bestatin through downregulating P-glycoprotein expression via inhibiting PI3K/Akt/mTOR pathway in K562/ADR cells. J Cell Biochem. 2016;117(5):1233-9.

110. Li Y, Revalde JL, Reid G, Paxton JW. Modulatory effects of curcumin on multi-drug resistance-associated protein 5 in pancreatic cancer cells. Cancer Chemother Pharmacol. 2011;68(3):603-10.

111. Wen C, Fu L, Huang J, Dai Y, Wang B, Xu G, et al. Curcumin reverses doxorubicin resistance via inhibition the efflux function of ABCB4 in doxorubicin-resistant breast cancer cells. Mol Med Rep. 2019;19(6):5162-8.

112. Bukowski K, Kciuk M, Kontek R. Mechanisms of multidrug resistance in cancer chemotherapy. Int J Mol Sci. 2020;21(9):3233.

113. Cho YA, Lee W, Choi JS. Effects of curcumin on the pharmacokinetics of tamoxifen and its active metabolite, 4-hydroxytamoxifen, in rats: possible role of CYP3A4 and P-glycoprotein inhibition by curcumin. Pharmazie. 2012;67(2):124-30.

114. Ramsay EE, Dilda PJ. Glutathione S-conjugates as prodrugs to target drug-resistant tumors. Front Pharmacol. 2014;5:181.

115. Pathania S, Bhatia R, Baldi A, Singh R, Rawal RK. Drug metabolizing enzymes and their inhibitors'role in cancer resistance. Biomed Pharmacothera. 2018;105:53-65.

116. Quiroga A, Quiroga PL, Martínez E, Soria EA, Valentich MA. Anti-breast cancer activity of curcumin on the human oxidation-resistant cells ZR-75-1 with gamma-glutamyltranspeptidase inhibition. J Exp Ther Oncol. 2010;8(3):261-6.

117. Ogiwara H, Takahashi K, Sasaki M, Kuroda T, Yoshida H, Watanabe R, et al. Targeting the vulnerability of glutathione metabolism in ARID1A-deficient cancers. Cancer Cell. 2019;35(2):177-90.e8.

118. Bansal A, Simon MC. Glutathione metabolism in cancer progression and treatment resistance. J Cell Biol. 2018;217(7):2291-8.

119. Desideri E, Ciccarone F, Ciriolo MR. Targeting glutathione metabolism: partner in crime in anticancer therapy. Nutrients. 2019;11(8):1926.

120. Lv H, Zhen C, Liu J, Yang P, Hu L, Shang P. Unraveling the potential role of glutathione in multiple forms of cell death in cancer therapy. Oxid Med Cell Longev. 2019;2019:3150145.

121. Aksoy M, Küfrevioglu I. Inhibition of human erythrocyte glutathione S-transferase by some flavonoid derivatives. Toxin Rev. 2018;37(3):251-7.

122. Hayeshi R, Mutingwende I, Mavengere W, Masiyanise V, Mukanganyama S. The inhibition of human glutathione S-transferases activity by plant polyphenolic compounds ellagic acid and curcumin. Food Chem Toxicol Int J Publ Br Indus Biol Res Assoc. 2007:45(2):286-95. 
123. Appiah-Opong R, Commandeur JN, Istyastono E, Bogaards JJ, Vermeulen NP. Inhibition of human glutathione S-transferases by curcumin and analogues. Xenobiotica Fate Foreign Compounds Biol Syst. 2009;39(4):302-11.

124. van Zanden JJ, Geraets L, Wortelboer HM, van Bladeren PJ, Rietjens IM, Cnubben NH. Structural requirements for the flavonoid-mediated modulation of glutathione S-transferase P1-1 and GS-X pump activity in MCF7 breast cancer cells. Biochem Pharmacol. 2004;67(8):1607-17.

125. Turek-Plewa J, Jagodziński PP. The role of mammalian DNA methyltransferases in the regulation of gene expression. Cell Mol Biol Lett. 2005;10(4):631-47.

126. Brown R, Curry E, Magnani L, Wilhelm-Benartzi CS, Borley J. Poised epigenetic states and acquired drug resistance in cancer. Nat Rev Cancer. 2014;14(11):747-53.

127. Wilting RH, Dannenberg JH. Epigenetic mechanisms in tumorigenesis, tumor cell heterogeneity and drug resistance. Drug Resist Updates Rev Comment Antimicrob Anticancer Chemothera. 2012;15(1-2):21-38.

128. Duan Z, Gao Y, Shen J, Choy E, Cote G, Harmon D, et al. miR-15b modulates multidrug resistance in human osteosarcoma in vitro and in vivo. Mol Oncol. 2017;11(2):151-66.

129. Deng Y, Bai H, Hu H. rs 11671784 G/A variation in miR-27a decreases chemo-sensitivity of bladder cancer by decreasing miR-27a and increasing the target RUNX-1 expression. Biochem Biophys Res Commun. 2015:458(2):321-7.

130. Joshi D, Chandrakala S, Korgaonkar S, Ghosh K, Vundinti BR. Down-regulation of miR-199b associated with imatinib drug resistance in 9q34.1 deleted BCR/ABL positive CML patients. Gene. 2014;542(2):109-12.

131. Zadi Heydarabad M, Vatanmakanian M, Abdolalizadeh J, Mohammadi H, Azimi A, Mousavi Ardehaie R, et al. Apoptotic effect of resveratrol on human T-ALL cell line CCRF-CEM is unlikely exerted through alteration of BAX and BCL2 promoter methylation. J Cell Biochem. 2018;119(12):10033-40.

132. Liu X, Li H, Wu ML, Wu J, Sun Y, Zhang KL, et al. Resveratrol reverses retinoic acid resistance of anaplastic thyroid cancer cells via demethylating CRABP2 gene. Front Endocrinol. 2019;10:734.

133. Zadi Heydarabad M, Nikasa M, Vatanmakanian M, Azimi A, Farshdousti HM. Regulatory effect of resveratrol and prednisolone on MDR1 gene expression in acute lymphoblastic leukemia cell line (CCRF-CEM): an epigenetic perspective. J Cell Biochem. 2018;119(6):4890-6.

134. Zhang X, Guo Q, Chen J, Chen Z. Quercetin enhances cisplatin sensitivity of human osteosarcoma cells by modulating microRNA-217-KRAS Axis. Mol Cells. 2015;38(7):638-42.

135. Wu H, Liu Q, Cai T, Chen YD, Wang ZF. Induction of microRNA-146a is involved in curcumin-mediated enhancement of temozolomide cytotoxicity against human glioblastoma. Mol Med Rep. 2015;12(4):5461-6.

136. Aggarwal A, Sharma N, Khera A, Sandhir R, Rishi V. Quercetin alleviates cognitive decline in ovariectomized mice by potentially modulating histone acetylation homeostasis. J Nutr Biochem. 2020;84:108439.

137. Devarshi PP, Jones AD, Taylor EM, Stefanska B, Henagan TM. Quercetin and quercetin-rich red onion extract alter Pgc-1a promoter methylation and splice variant expression. PPAR Res. 2017;2017:3235693.

138. Roy M, Mukherjee S. Reversal of resistance towards cisplatin by curcumin in cervical cancer cells. Asian Pac J Cancer Prev APJCP. 2014;15(3):1403-10.

139. Royt M, Mukherjee S, Sarkar R, Biswas J. Curcumin sensitizes chemotherapeutic drugs via modulation of PKC, telomerase, NF-kappaB and HDAC in breast cancer. Ther Deliv. 2011;2(10):1275-93.

140. Zhang J, Liu J, XU X, Li L. Curcumin suppresses cisplatin resistance development partly via modulating extracellular vesicle-mediated transfer of MEG3 and miR-214 in ovarian cancer. Cancer Chemother Pharmacol. 2017;79(3):479-87.

141. Zhou S, Li J, Xu H, Zhang S, Chen X, Chen W, et al. Liposomal curcumin alters chemosensitivity of breast cancer cells to Adriamycin via regulating microRNA expression. Gene. 2017;622:1-12.

142. Liu JM, Li M, Luo W, Sun HB. Curcumin attenuates Adriamycin-resistance of acute myeloid leukemia by inhibiting the IncRNA HOTAIR/miR-20a-5p/WT1 axis. Lab Investig J Tech Methods Pathol. 2021;101(10):1308-17

143. Noratto GD, Jutooru I, Safe S, Angel-Morales G, Mertens-Talcott SU. The drug resistance suppression induced by curcuminoids in colon cancer SW-480 cells is mediated by reactive oxygen species-induced disruption of the microRNA-27a-ZBTB10-Sp axis. Mol Nutr Food Res. 2013;57(9):1638-48.

144. Lu Y, Wang J, Liu L, Yu L, Zhao N, Zhou X, et al. Curcumin increases the sensitivity of Paclitaxel-resistant NSCLC cells to Paclitaxel through microRNA-30c-mediated MTA1 reduction. Tumour Biol J Int Soc Oncodev Biol Med. 2017:39(4):1010428317698353.

145. Lin L, Baehrecke EH. Autophagy, cell death, and cancer. Mol Cell Oncol. 2015;2(3):e985913.

146. Carneiro BA, El-Deiry WS. Targeting apoptosis in cancer therapy. Nat Rev Clin Oncol. 2020;17(7):395-417.

147. Mohammad RM, Muqbil I, Lowe L, Yedjou C, Hsu HY, Lin LT, et al. Broad targeting of resistance to apoptosis in cancer. Semin Cancer Biol. 2015;35(Suppl_0):S78-103.

148. Sui X, Chen R, Wang Z, Huang Z, Kong N, Zhang M, et al. Autophagy and chemotherapy resistance: a promising therapeutic target for cancer treatment. Cell Death Dis. 2013;4(10):e838.

149. Smith AG, Macleod KF. Autophagy, cancer stem cells and drug resistance. J Pathol. 2019;247(5):708-18.

150. Chen $P$, Huang HP, Wang $Y$, Jin J, Long WG, Chen $K$, et al. Curcumin overcome primary gefitinib resistance in non-small-cell lung cancer cells through inducing autophagy-related cell death. J Exp Clin Cancer Res CR. 2019;38(1):254

151. Chang CH, Lee CY, Lu CC, Tsai FJ, Hsu YM, Tsao JW, et al. Resveratrol-induced autophagy and apoptosis in cisplatin-resistant human oral cancer CAR cells: a key role of AMPK and Akt/mTOR signaling. Int J Oncol. 2017:50(3):873-82.

152. Xie X, Yin J, Jia Q, Wang J, Zou C, Brewer KJ, et al. Quercetin induces apoptosis in the methotrexate-resistant osteosarcoma cell line U2-OS/MTX300 via mitochondrial dysfunction and dephosphorylation of Akt. Oncol Rep. 2011;26(3):687-93.

153. Chen FY, Cao LF, Wan HX, Zhang MY, Cai JY, Shen LJ, et al. Quercetin enhances adriamycin cytotoxicity through induction of apoptosis and regulation of mitogen-activated protein kinase/extracellular signalregulated kinase/c-Jun N-terminal kinase signaling in multidrug-resistant leukemia K562 cells. Mol Med Rep. 2015;11(1):341-8 
154. Yuan CH, Horng CT, Lee CF, Chiang NN, Tsai FJ, Lu CC, et al. Epigallocatechin gallate sensitizes cisplatin-resistant oral cancer CAR cell apoptosis and autophagy through stimulating AKT/STAT3 pathway and suppressing multidrug resistance 1 signaling. Environ Toxicol. 2017;32(3):845-55.

155. Zhang $\mathrm{P}$, Lai ZL, Chen HF, Zhang M, Wang A, Jia T, et al. Curcumin synergizes with 5-fluorouracil by impairing AMPK/ULK1-dependent autophagy, AKT activity and enhancing apoptosis in colon cancer cells with tumor growth inhibition in xenograft mice. J Exp Clin Cancer Res CR. 2017;36(1):190.

156. Deng L, Wu X, Zhu X, Yu Z, Liu Z, Wang J, et al. Combination effect of curcumin with docetaxel on the PI3K/AKT/ mTOR pathway to induce autophagy and apoptosis in esophageal squamous cell carcinoma. Am J Transl Res. 2021;13(1):57-72.

157. Zhu Y, He W, Gao X, Li B, Mei C, Xu R, et al. Resveratrol overcomes gefitinib resistance by increasing the intracellular gefitinib concentration and triggering apoptosis, autophagy and senescence in PC9/G NSCLC cells. Sci Rep. 2015;5:17730.

158. Chen $\mathrm{X}, \mathrm{Xu} \mathrm{H}$, Yu X, Wang $\mathrm{X}$, Zhu X, Xu X. Apigenin inhibits in vitro and in vivo tumorigenesis in cisplatin-resistant colon cancer cells by inducing autophagy, programmed cell death and targeting m-TOR/PI3K/Akt signalling pathway. J BUON Off J Balkan Union Oncol. 2019;24(2):488-93.

159. Wei F, Jiang X, Gao HY, Gao SH. Liquiritin induces apoptosis and autophagy in cisplatin (DDP)-resistant gastric cancer cells in vitro and xenograft nude mice in vivo. Int J Oncol. 2017;51(5):1383-94.

160. Yang Y, Liao Y, Gui YP, Zhao L, Guo LB. GL-V9 reverses adriamycin resistance in hepatocellular carcinoma cells by affecting JNK2-related autophagy. Chin J Nat Med. 2020;18(7):491-9.

161. Li Z, Pearlman AH, Hsieh P. DNA mismatch repair and the DNA damage response. DNA Repair. 2016:38:94-101.

162. Jackson SP, Bartek J. The DNA-damage response in human biology and disease. Nature. 2009;461 (7267):1071-8.

163. Kaina B, Christmann M. DNA repair in personalized brain cancer therapy with temozolomide and nitrosoureas. DNA Repair. 2019;78:128-41.

164. Heyza JR, Arora S, Zhang H, Conner KL, Lei W, Floyd AM, et al. Targeting the DNA repair endonuclease ERCC1-XPF with green tea polyphenol epigallocatechin-3-gallate (EGCG) and its prodrug to enhance cisplatin efficacy in human cancer cells. Nutrients. 2018;10(11):1644.

165. Tsai MS, Weng SH, Kuo YH, Chiu YF, Lin YW. Synergistic effect of curcumin and cisplatin via down-regulation of thymidine phosphorylase and excision repair cross-complementary 1 (ERCC1). Mol Pharmacol. 2011;80(1):136-46.

166. Chen Y, Hong C, Chen X, Qin Z. Demethoxycurcumin increases the sensitivity of cisplatin-resistant non-small lung cancer cells to cisplatin and induces apoptosis by activating the caspase signaling pathway. Oncol Lett. 2020;20(5):209.

167. Chen P, Li J, Jiang HG, Lan T, Chen YC. Curcumin reverses cisplatin resistance in cisplatin-resistant lung caner cells by inhibiting FA/BRCA pathway. Tumour Biol J Int Soc Oncodev Biol Med. 2015:36(5):3591-9.

168. Nowacka-Zawisza M, Bryś M, Romanowicz-Makowska H, Kulig A, Krajewska WM. Genetic instability in the RAD51 and BRCA1 regions in breast cancer. Cell Mol Biol Lett. 2007;12(2):192-205.

169. Leon-Galicia I, Diaz-Chavez J, Albino-Sanchez ME, Garcia-Villa E, Bermudez-Cruz R, Garcia-Mena J, et al. Resveratrol decreases Rad51 expression and sensitizes cisplatin-resistant MCF-7 breast cancer cells. Oncol Rep. 2018;39(6):3025-33.

170. Li H, Liu Y, Jiao Y, Guo A, Xu X, Qu X, et al. Resveratrol sensitizes glioblastoma-initiating cells to temozolomide by inducing cell apoptosis and promoting differentiation. Oncol Rep. 2016;35(1):343-51.

171. Garcia-Mayea Y, Mir C, Masson F, Paciucci R, Lleonart ME. Insights into new mechanisms and models of cancer stem cell multidrug resistance. Semin Cancer Biol. 2020;60:166-80.

172. Lytle NK, Barber AG, Reya T. Stem cell fate in cancer growth, progression and therapy resistance. Nat Rev Cancer. 2018:18(11):669-80

173. Cao HZ, Liu XF, Yang WT, Chen Q, Zheng PS. LGR5 promotes cancer stem cell traits and chemoresistance in cervical cancer. Cell Death Dis. 2017:8(9):e3039.

174. Chaudhary AK, Mondal G, Kumar V, Kattel K, Mahato RI. Chemosensitization and inhibition of pancreatic cancer stem cell proliferation by overexpression of microRNA-205. Cancer Lett. 2017;402:1-8.

175. Cheng S, Huang Y, Lou C, He Y, Zhang Y, Zhang Q. FSTL1 enhances chemoresistance and maintains stemness in breast cancer cells via integrin $\beta 3 / W n t$ signaling under miR-137 regulation. Cancer Biol Ther. 2019;20(3):328-37.

176. Jung J, Kim S, An HT, Ko J. a-Actinin-4 regulates cancer stem cell properties and chemoresistance in cervical cancer. Carcinogenesis. 2020;41(7):940-9.

177. Lu H, Ju DD, Yang GD, Zhu LY, Yang XM, Li J, et al. Targeting cancer stem cell signature gene SMOC-2 Overcomes chemoresistance and inhibits cell proliferation of endometrial carcinoma. EBioMedicine. 2019;40:276-89.

178. Wang T, Fahrmann JF, Lee H, Li YJ, Tripathi SC, Yue C, et al. JAK/STAT3-regulated fatty acid $\beta$-oxidation is critical for breast cancer stem cell self-renewal and chemoresistance. Cell Metab. 2018;27(1):136-50.e5.

179. Ward Rashidi MR, Mehta P, Bregenzer M, Raghavan S, Fleck EM, Horst EN, et al. Engineered 3D model of cancer stem cell enrichment and chemoresistance. Neoplasia (New York, NY). 2019;21(8):822-36.

180. Xiang X, Deng L, Xiong R, Xiao D, Chen Z, Yang F, et al. Tex 10 is upregulated and promotes cancer stem cell properties and chemoresistance in hepatocellular carcinoma. Cell Cycle (Georgetown, Tex). 2018;17(11):1310-8.

181. Chi HC, Tsai CY, Wang CS, Yang HY, Lo CH, Wang WJ, et al. DOCK6 promotes chemo- and radioresistance of gastric cancer by modulating WNT/ $\beta$-catenin signaling and cancer stem cell traits. Oncogene. 2020;39(37):5933-49.

182. Park SY, Lee CJ, Choi JH, Kim JH, Kim JW, Kim JY, et al. The JAK2/STAT3/CCND2 Axis promotes colorectal cancer stem cell persistence and radioresistance. J Exp Clin Cancer Res CR. 2019;38(1):399.

183. Troschel FM, Böhly N, Borrmann K, Braun T, Schwickert A, Kiesel L, et al. miR-142-3p attenuates breast cancer stem cell characteristics and decreases radioresistance in vitro. Tumour Biol J Int Soc Oncodev Biol Med. 2018;40(8):1010428318791887.

184. Tsao T, Beretov J, Ni J, Bai X, Bucci J, Graham P, et al. Cancer stem cells in prostate cancer radioresistance. Cancer Lett. 2019;465:94-104.

185. Eun K, Ham SW, Kim H. Cancer stem cell heterogeneity: origin and new perspectives on CSC targeting. BMB Rep. 2017;50(3):117-25. 
186. Najafi M, Mortezaee K, Majidpoor J. Cancer stem cell (CSC) resistance drivers. Life Sci. 2019;234:116781.

187. Galoczova M, Coates P, Vojtesek B. STAT3, stem cells, cancer stem cells and p63. Cell Mol Biol Lett. 2018;23:12

188. Su P, Yang Y, Wang G, Chen X, Ju Y. Curcumin attenuates resistance to irinotecan via induction of apoptosis of cancer stem cells in chemoresistant colon cancer cells. Int J Oncol. 2018;53(3):1343-53.

189. Yoshida K, Toden S, Ravindranathan P, Han H, Goel A. Curcumin sensitizes pancreatic cancer cells to gemcitabine by attenuating PRC2 subunit EZH2, and the IncRNA PVT1 expression. Carcinogenesis. 2017;38(10):1036-46.

190. Marquardt JU, Gomez-Quiroz L, Arreguin Camacho LO, Pinna F, Lee YH, Kitade M, et al. Curcumin effectively inhibits oncogenic NF-KB signaling and restrains stemness features in liver cancer. J Hepatol. 2015;63(3):661-9.

191. Kuo YC, Wang $L$, Rajesh R. Targeting human brain cancer stem cells by curcumin-loaded nanoparticles grafted with anti-aldehyde dehydrogenase and sialic acid: Colocalization of ALDH and CD44. Mater Sci Eng C Mater Biol Appl. 2019:102:362-72.

192. Toden S, Okugawa Y, Jascur T, Wodarz D, Komarova NL, Buhrmann C, et al. Curcumin mediates chemosensitization to 5-fluorouracil through miRNA-induced suppression of epithelial-to-mesenchymal transition in chemoresistant colorectal cancer. Carcinogenesis. 2015;36(3):355-67.

193. Zhou QM, Sun Y, Lu YY, Zhang H, Chen QL, Su SB. Curcumin reduces mitomycin C resistance in breast cancer stem cells by regulating BCl-2 family-mediated apoptosis. Cancer Cell Int. 2017;17:84.

194. Zhou Q, Ye M, Lu Y, Zhang H, Chen Q, Huang S, et al. Curcumin improves the tumoricidal effect of mitomycin C by suppressing ABCG2 expression in stem cell-like breast cancer cells. PLoS ONE. 2015;10(8):e0136694.

195. Li YJ, Wu SL, Lu SM, Chen F, Guo Y, Gan SM, et al. (-)-Epigallocatechin-3-gallate inhibits nasopharyngeal cancer stem cell self-renewal and migration and reverses the epithelial-mesenchymal transition via NF-KB p65 inactivation. Tumour Biol I Int Soc Oncodev Biol Med. 2015;36(4):2747-61.

196. Wang Y, Wang H, Zhou R, Zhong W, Lu S, Ma Z, et al. Baicalin inhibits human osteosarcoma cells invasion, metastasis, and anoikis resistance by suppressing the transforming growth factor- $\beta 1$-induced epithelial-to-mesenchymal transition. Anticancer Drugs. 2017;28(6):581-7.

197. Yu M, Qi B, Xiaoxiang W, Xu J, Liu X. Baicalein increases cisplatin sensitivity of A549 lung adenocarcinoma cells via PI3K/Akt/NF-KB pathway. Biomed Pharmacothera. 2017;90:677-85.

198. Toden S, Tran HM, Tovar-Camargo OA, Okugawa Y, Goel A. Epigallocatechin-3-gallate targets cancer stem-like cells and enhances 5-fluorouracil chemosensitivity in colorectal cancer. Oncotarget. 2016;7(13):16158-71.

199. Kim EK, Jang M, Song MJ, Kim D, Kim Y, Jang HH. Redox-mediated mechanism of chemoresistance in cancer cells. Antioxidants (Basel, Switzerland). 2019;8(10):471.

200. Cui Q, Wang JQ, Assaraf YG, Ren L, Gupta P, Wei L, et al. Modulating ROS to overcome multidrug resistance in cancer. Drug Resist Updates Rev Comment Antimicrob Anticancer Chemothera. 2018;41:1-25.

201. Mohammadi F, Soltani A, Ghahremanloo A, Javid H, Hashemy SI. The thioredoxin system and cancer therapy: a review. Cancer Chemother Pharmacol. 2019;84(5):925-35.

202. Ai Y, Zhu B, Ren C, Kang F, Li J, Huang Z, et al. Discovery of new monocarbonyl ligustrazine-curcumin hybrids for intervention of drug-sensitive and drug-resistant lung cancer. J Med Chem. 2016;59(5):1747-60.

203. Zhou B, Huang J, Zuo Y, Li B, Guo Q, Cui B, et al. 2a, a novel curcumin analog, sensitizes cisplatin-resistant A549 cells to cisplatin by inhibiting thioredoxin reductase concomitant oxidative stress damage. Eur J Pharmacol. 2013;707(1-3):130-9.

204. Suzuki T, Yamamoto M. Stress-sensing mechanisms and the physiological roles of the Keap1-Nrf2 system during cellular stress. J Biol Chem. 2017;292(41):16817-24.

205. Zhang C, Wang HJ, Bao QC, Wang L, Guo TK, Chen WL, et al. NRF2 promotes breast cancer cell proliferation and metastasis by increasing RhoA/ROCK pathway signal transduction. Oncotarget. 2016;7(45):73593-606.

206. DeNicola GM, Karreth FA, Humpton TJ, Gopinathan A, Wei C, Frese K, et al. Oncogene-induced Nrf2 transcription promotes ROS detoxification and tumorigenesis. Nature. 2011;475(7354):106-9.

207. Rojo Al, Rada P, Mendiola M, Ortega-Molina A, Wojdyla K, Rogowska-Wrzesinska A, et al. The PTEN/NRF2 axis promotes human carcinogenesis. Antioxid Redox Signal. 2014;21(18):2498-514.

208. Dauer P, Sharma NS, Gupta VK, Nomura A, Dudeja V, Saluja A, et al. GRP78-mediated antioxidant response and ABC transporter activity confers chemoresistance to pancreatic cancer cells. Mol Oncol. 2018;12(9):1498-512.

209. Wu J, Bao L, Zhang Z, Yi X. Nrf2 induces cisplatin resistance via suppressing the iron export related gene SLC40A1 in ovarian cancer cells. Oncotarget. 2017;8(55):93502-15.

210. Liu D, Zhang Y, Wei Y, Liu G, Liu Y, Gao Q, et al. Activation of AKT pathway by Nrf2/PDGFA feedback loop contributes to HCC progression. Oncotarget. 2016;7(40):65389-402.

211. Panieri E, Saso L. Potential applications of NRF2 inhibitors in cancer therapy. Oxid Med Cell Longev. 2019:2019:8592348

212. Zhang C, He $L$, Ye HZ, Liu DF, Zhu YB, Miao DD, et al. Nrf2 is a key factor in the reversal effect of curcumin on multidrug resistance in the HCT-8/5-Fu human colorectal cancer cell line. Mol Med Rep. 2018;18(6):5409-16.

213. Fetoni AR, Paciello F, Mezzogori D, Rolesi R, Eramo SL, Paludetti G, et al. Molecular targets for anticancer redox chemotherapy and cisplatin-induced ototoxicity: the role of curcumin on PSTAT3 and Nrf-2 signalling. Br J Cancer. 2015;113(10):1434-44.

214. Cheng L, Yan B, Chen K, Jiang Z, Zhou C, Cao J, et al. Resveratrol-induced downregulation of NAF-1 enhances the sensitivity of pancreatic cancer cells to gemcitabine via the ROS/Nrf2 signaling pathways. Oxid Med Cell Longev. 2018;2018:9482018.

215. Esmaeili MA. Combination of siRNA-directed gene silencing with epigallocatechin-3-gallate (EGCG) reverses drug resistance in human breast cancer cells. J Chem Biol. 2016;9(1):41-52.

216. Chen TC, Chuang JY, Ko CY, Kao TJ, Yang PY, Yu CH, et al. AR ubiquitination induced by the curcumin analog suppresses growth of temozolomide-resistant glioblastoma through disrupting GPX4-Mediated redox homeostasis. Redox Biol. 2020:30:101413.

217. Gao AM, Ke ZP, Shi F, Sun GC, Chen H. Chrysin enhances sensitivity of BEL-7402/ADM cells to doxorubicin by suppressing PI3K/Akt/Nrf2 and ERK/Nrf2 pathway. Chem Biol Interact. 2013;206(1):100-8. 
218. Lamouille S, Xu J, Derynck R. Molecular mechanisms of epithelial-mesenchymal transition. Nat Rev Mol Cell Biol. 2014;15(3):178-96.

219. Gonzalez DM, Medici D. Signaling mechanisms of the epithelial-mesenchymal transition. Sci Signal. 2014;7(344):8.

220. Du B, Shim JS. Targeting epithelial-mesenchymal transition (EMT) to overcome drug resistance in cancer. Molecules (Basel, Switzerland). 2016;21(7):965.

221. Saxena M, Stephens MA, Pathak H, Rangarajan A. Transcription factors that mediate epithelial-mesenchymal transition lead to multidrug resistance by upregulating ABC transporters. Cell Death Dis. 2011;2(7):e179.

222. Sui H, Zhu L, Deng W, Li Q. Epithelial-mesenchymal transition and drug resistance: role, molecular mechanisms, and therapeutic strategies. Oncol Res Treat. 2014;37(10):584-9.

223. Lu Y, Zhang R, Zhang X, Zhang B, Yao Q. Curcumin may reverse 5 -fluorouracil resistance on colonic cancer cells by regulating TET1-NKD-Wnt signal pathway to inhibit the EMT progress. Biomed Pharmacothera. 2020;129:110381.

224. Zhang C, Xu Y, Wang H, Li G, Yan H, Fei Z, et al. Curcumin reverses irinotecan resistance in colon cancer cell by regulation of epithelial-mesenchymal transition. Anticancer Drugs. 2018;29(4):334-40.

225. Yin J, Wang L, Wang Y, Shen H, Wang X, Wu L. Curcumin reverses oxaliplatin resistance in human colorectal cancer via regulation of TGF- $\beta /$ Smad2/3 signaling pathway. Onco Targets Ther. 2019;12:3893-903.

226. Cai J, Sun H, Zheng B, Xie M, Xu C, Zhang G, et al. Curcumin attenuates IncRNA H19-induced epithelial-mesenchymal transition in\&nbsp;tamoxifen-resistant breast cancer cells. Mol Med Rep. 2021;23(1):1.

227. Buhrmann C, Shayan P, Kraehe P, Popper B, Goel A, Shakibaei M. Resveratrol induces chemosensitization to 5-fluorouracil through up-regulation of intercellular junctions, epithelial-to-mesenchymal transition and apoptosis in colorectal cancer. Biochem Pharmacol. 2015;98(1):51-68.

228. Shen YA, Lin CH, Chi WH, Wang CY, Hsieh YT, Wei YH, et al. Resveratrol impedes the stemness, epithelial-mesenchymal transition, and metabolic reprogramming of cancer stem cells in nasopharyngeal carcinoma through p53 activation. Evid Based Complement Altern Med eCAM. 2013;2013:590393.

229. Jin X, Wei Y, Liu Y, Lu X, Ding F, Wang J, et al. Resveratrol promotes sensitization to Doxorubicin by inhibiting epithelial-mesenchymal transition and modulating SIRT1/ $\beta$-catenin signaling pathway in breast cancer. Cancer Med. 2019;8(3):1246-57.

230. Xu J, Liu D, Niu H, Zhu G, Xu Y, Ye D, et al. Resveratrol reverses Doxorubicin resistance by inhibiting epithelial-mesenchymal transition (EMT) through modulating PTEN/Akt signaling pathway in gastric cancer. J Exp Clin Cancer Res CR. 2017;36(1):19.

231. Lu X, Yang F, Chen D, Zhao Q, Chen D, Ping H, et al. Quercetin reverses docetaxel resistance in prostate cancer via androgen receptor and PI3K/Akt signaling pathways. Int J Biol Sci. 2020;16(7):1121-34.

232. Lin $\mathrm{CH}$, Shen YA, Hung PH, Yu YB, Chen YJ. Epigallocathechin gallate, polyphenol present in green tea, inhibits stem-like characteristics and epithelial-mesenchymal transition in nasopharyngeal cancer cell lines. BMC Complement Altern Med. 2012;12:201

233. Ko H. Geraniin inhibits TGF- $\beta 1$-induced epithelial-mesenchymal transition and suppresses A549 lung cancer migration, invasion and anoikis resistance. Bioorg Med Chem Lett. 2015;25(17):3529-34.

234. Popat R, Plesner T, Davies F, Cook G, Cook M, Elliott P, et al. A phase 2 study of SRT501 (resveratrol) with bortezomib for patients with relapsed and or refractory multiple myeloma. Br J Haematol. 2013;160(5):714-7.

235. Kanai M, Yoshimura K, Asada M, Imaizumi A, Suzuki C, Matsumoto S, et al. A phase I/II study of gemcitabine-based chemotherapy plus curcumin for patients with gemcitabine-resistant pancreatic cancer. Cancer Chemother Pharmacol. 2011;68(1):157-64

\section{Publisher's Note}

Springer Nature remains neutral with regard to jurisdictional claims in published maps and institutional affiliations.

Ready to submit your research? Choose BMC and benefit from:

- fast, convenient online submission

- thorough peer review by experienced researchers in your field

- rapid publication on acceptance

- support for research data, including large and complex data types

- gold Open Access which fosters wider collaboration and increased citations

- maximum visibility for your research: over 100M website views per year

At BMC, research is always in progress.

Learn more biomedcentral.com/submissions 